IZA DP No. 6962

Does Mother Know Best?

Parental Discrepancies in Assessing Child Functioning

Nabanita Datta Gupta

Mette Lausten

Dario Pozzoli

October 2012 


\title{
Does Mother Know Best? Parental Discrepancies in Assessing Child Functioning
}

\author{
Nabanita Datta Gupta \\ Aarhus University and IZA \\ Mette Lausten \\ Danish National Centre for Social Research \\ Dario Pozzoli \\ Aarhus University and IZA
}
Discussion Paper No. 6962
October 2012

\author{
IZA \\ P.O. Box 7240 \\ 53072 Bonn \\ Germany \\ Phone: +49-228-3894-0 \\ Fax: +49-228-3894-180 \\ E-mail: iza@iza.org
}

\begin{abstract}
Any opinions expressed here are those of the author(s) and not those of IZA. Research published in this series may include views on policy, but the institute itself takes no institutional policy positions. The IZA research network is committed to the IZA Guiding Principles of Research Integrity.

The Institute for the Study of Labor (IZA) in Bonn is a local and virtual international research center and a place of communication between science, politics and business. IZA is an independent nonprofit organization supported by Deutsche Post Foundation. The center is associated with the University of Bonn and offers a stimulating research environment through its international network, workshops and conferences, data service, project support, research visits and doctoral program. IZA engages in (i) original and internationally competitive research in all fields of labor economics, (ii) development of policy concepts, and (iii) dissemination of research results and concepts to the interested public.
\end{abstract}

IZA Discussion Papers often represent preliminary work and are circulated to encourage discussion. Citation of such a paper should account for its provisional character. A revised version may be available directly from the author. 


\section{ABSTRACT \\ Does Mother Know Best? Parental Discrepancies in Assessing Child Functioning*}

We investigate the degree of correspondence between parents' reports on child behavioral and educational outcomes using the most recent available wave of a rich Danish longitudinal survey of children (the DALSC). All outcomes are measured at age 11 when the children are expected to be in fifth grade. Once discrepancies are detected, we analyze whether they are driven by noisy evaluations or by systematic bias, focusing on the role of parental characteristics and response heterogeneity. We then explicitly assess the relative importance of the mother's versus the father's assessments in explaining child academic performance and diagnosed mental health to investigate whether one parent is systematically a better informant of their child's outcomes than the other.

JEL Classification: $\quad$ I12, J13

Keywords: child development, informant discrepancies, reporting bias

Corresponding author:

Dario Pozzoli

Aarhus University

Department of Economics and Business

Fuglesangs Allé 4

8210 Aarhus

Denmark

E-mail: dpozzoli@asb.dk

\footnotetext{
* Permission to use the DALSC data was granted by SFI-The Danish National Centre for Social Research. Funding from the Strategic Research Council on Education is gratefully acknowledged. Teresa Bago d'Uva, Francine Blau, Paul Bingley, Laure de Preux Gallon, Pilar Garcia, Anders Holm, Mads Meier Jæger, Larry Kahn, Heather Mattson, Helena Skyt Nielsen, David Reimer and Astrid Würtz Rasmussen are thanked for helpful comments and suggestions. In addition, we appreciate comments from participants at the AIEL conference in Napoli and at the seminars organized by the Department of Economics, Erasmus University, the Department of Education, Aarhus University and the Centre for Strategic Education Research (CSER). The usual disclaimer applies.
} 


\section{Introduction}

An unusually large and extensive interdisciplinary literature has investigated the socioeconomic determinants of early childhood conditions. Interest in this research area has been spurred by a growing realization that early life conditions can have a profound impact on later life. Several studies (Case, Fertig, and Paxson 2005; McLeod and Kaiser 2004; Blanden, Gregg, and Macmillan 2006) suggest that characteristics measured as of age 7 can explain a great deal of the variation in educational attainment, earnings and employment probability as of early 30s. Some studies have investigated the relationship between parental income and the health of their children, i.e. the income gradient (Case, Lubotsky, and Paxson 2002; Currie and Stabile 2003; Currie, Shields, and Wheatley Price 2007). Others have focused on the relationship between child development and non-parental care (Baker, Gruber and Milligan, 2008; Bernal and Keane, 2011; Blau and Currie 2008; Brown et al. 2006; Datta Gupta and Simonsen 2010, 2012; Havnes and Mogstad 2011). While studies from US and Canada have found negative effects of child care on children and families (Baker, Gruber and Milligan 2008; Bernal and Keane 2011), the evidence from Scandinavian countries tend to show positive effects: some of these studies looking at mature schemes find that early intervention programs have only short-term effects on non-cognitive skills (Datta Gupta and Simonsen 2010 and 2012), while others provide evidence of strong positive effects also on children's long run outcomes, as adult, of the introduction of universal child care (Havnes and Mogstad 2011).

Research on early child development is in most cases based on subjective evaluations of a given category of child functioning -behavioral, emotional, cognitive etc.- and very often these assessments come from mothers rather than other informants. Clinicians and researchers, for example, view mothers as being most accurate in reporting children's eventual behavioral and emotional problems but tend to neglect fathers as possible informants of children's outcomes (Treutler and Epkins 2003). However, the reliability of the assessments of child outcomes and behavior has been generally questioned. Firstly, there are concerns about the extent to which these measures of school outcomes and health are validated by more objective 
measures. Baker, Stabile, and Deri (2004) found, for example, very limited evidence on the correspondence between self-reported health measures and medical records. Secondly, respondents may have different motivations for providing ratings of children and have different thresholds or perceptions of what constitutes a normal functioning in a given child (Bago d'Uva et al. 2007; Lindeboom and van Doorslaer 2004). Finally, the very poor agreement for different informants' ratings of a given child's functioning raises concerns about the relative validity of any single source of information.

Because of this low to moderate correspondence between the information provided by different informants, the literature has tried to investigate the determinants of informant discrepancies (Johnston et al., 2010). Some studies have examined how child characteristics age, gender, ethnicity and problem type - are related to informant discrepancies (Achenbach, McConaughy, and Howell 1987; Kolko and Kazdin 1993; Duhig et al. 2000). Other works have focused on the role of parents' characteristics, such as their socio-economic status (Treutler and Epkins 2003), their levels of psychopathology (Krain and Kendall 2000), and of family characteristics, like the family status, the sibling birth order, the number of siblings and the familiarity of the child to the parent (Jensen et al. 1988; Treutler and Epkins 2003).

However, no clear pattern of correlation has been found between informant discrepancies and the previously mentioned characteristics. The current state of the literature is characterized by inconsistent findings and does not provide adequate conclusions as to the magnitude of the relations involved. Interestingly, the inconsistency of prior work is due to the fact that some of the relations are spurious and are explained by other informant characteristics. Moreover, no theoretical rationale has been provided to explain these discrepancies and, as a result, no formal tests have been conducted to examine the processes involved. Consequently, remarkably little is known about why parents' ratings of children's functioning often diverge from one and another's. However, understanding the source of these discrepancies is extremely relevant because relying on one parent than another, or even combining assessments from both parents, can lead to different conclusions regarding the determinants of child cognitive, emotional, social and behavioral outcomes. Johnston et al. (2010), for 
example, finds that using different informants' ratings results in systematic differences in the estimated magnitude and significance of the health-income gradient. Moreover, Becker and Tomes (1986) developed a model in which the rate of return to parental human capital investments in their children depended positively on their endowment of abilities. Biased reports of child "ability" (behavior or academic performance) can therefore lead to an inefficient allocation of parental investments during childhood having long lasting effects, as parental responses are considered to be important in either magnifying or mitigating the effects of a shock in early childhood on subsequent outcomes (Almond and Currie 2010).

To shed light on parental discrepancies, the present study addresses several important research questions. First, using the most recent available wave of the Danish Longitudinal Survey of Children (DALSC), we investigate the degree of correspondence between parents' reports on child outcomes. To this purpose, we use both reported behavioral outcomes (the mother and the father versions of the Strength and Difficulties Questionnaire, SDQ) and reported educational outcomes (the mother and the father versions of a set of questions about school performance). All these outcomes are measured at age 11, when the children are expected to be in fifth grade. Second, when discrepancies are detected, we analyze whether they are driven by noisy evaluations or by systematic bias, mainly focusing on the role of parents' characteristics. We also explicitly investigate whether specific parents' characteristics affect their way of perceiving and responding to the survey questions regarding their child, by estimating a generalized ordered probit. Finally, we assess the relative importance of the mother's versus the father's assessments in explaining child functioning, to investigate whether mothers are systematically better informants of children's outcomes than fathers, as claimed by clinicians.

The paper is organized as follows. Section II highlights the main theoretical relations. Section III introduces the data set and presents main descriptive statistics. Section IV provides details on the empirical strategy. Section V explains the results of the empirical analysis and section VI offers some concluding remarks. 


\section{Theoretical background}

Our empirical analysis on informant discrepancies is guided by a framework which is based on theories of the influence of perspectives (Tversky and March 2000), social desirability (Silverman and Rabian 1995) and social tightness (Prendergast and Topel 1996; Prendergast 2002).

Discrepancies between a pair of observers may rise because of a difference in perspectives. Parental psychopathology frames a parent's perspective for providing information of her/his child's problems or negative behaviors, i.e. a perspective that influences parent recall of the more negative aspects of the child's problems. Mood congruent biases in recall are a possible mechanism for this type of differential reporting. Parental depression may decrease the threshold by which one of the two parents gauge whether a child's behavior is problematic or not. This lower threshold may lead to one parent's perspectives diverging from the perspectives of the other parent. Mothers' depression, for example, is often asserted to be a distorting variable in mother reports on child behavior, in that maternal depression is associated with reporting more negative behavior than other ratings indicate (Youngstrom, Izard, and Ackerman 1999; Youngstrom, Findling, and Calabrese 2003). This "depressiondistortion hypothesis" also finds support when mothers' reporting of children's symptoms, or over-reporting of symptoms relative to other sources, relate to their anxiety, stress and to psychological symptoms in general (Renk, Phares, and Epps 1999). Furthermore, differences in perspectives may also arise because of differences in educational and ethnic background. Cultural differences in parenting practices and rules for interpersonal behavior, such as the use of physical punishment, verbal aggression or guilt and shame induction, are all likely to influence which child behaviors are considered problematic.

An alternative view is that some informants may show a systematic tendency to report less negative events and behavior than others. Issues of social desirability may explain why one of the two parents has more incentives to deny or minimize socially undesirable symptoms than the other one. Typically, this is a concern when information relating to common societal 
taboos such as illicit drug use, engaging in illegal activities or sexual promiscuity is elicited. However, social desirability bias may also arise in over-reports of own or child abilities and achievements, for instance, to gain status within one's circle of peers. Respondents might misrepresent and misreport child outcomes also to project a favorable impression to the surveyor (Fisher 1993; Presser and Stinson 1998).

Finally, the relationship between the informants and the ratee under investigation contributes to informants' reports and to the discrepancies between informants' reports. The parent-child relationship may be related to the father-mother discrepancies for two main reasons. Firstly, both quantitative (i.e. time spent taking care of the child and doing things with the child) and qualitative (parental acceptance of the child) aspects of parental involvement may affect parents' awareness of child behavioral and emotional problems. Thus, the parent having a more intense relationship with the child may be a more accurate informant on the child functioning than other sources. This is especially true for internalizing or emotional problems, e.g. child anxiety and depression, which are less observable compared to the child externalizing problems, e.g. hyperactivity and oppositional behavior. In this sense, we can reasonably expect lower levels of correspondence for parents' ratings of child internalizing problems compared with parents' rating of child externalizing problems, in case of a differential in the degree of familiarity of the child to the parents. Secondly, the degree of acquaintance between the parent and the child may affect the accuracy of the ratings. A closer social attachment between one of the parents and the child can lead to different parental ratings even if there is no difference in true child functioning. Prendergast and Topel (1996) and Prendergast (2002) analyze subjective appraisals in economic models assuming that supervisors, while having some intrinsic preference for accurately reporting the true performance, also care for the welfare of their ratees. This leads to a basic tradeoff between accuracy and leniency and it directly results in more lenient ratings, the stronger the supervisor's social preferences toward the evaluated subordinate. Based on this reasoning, it is possible to argue that a closer social attachment between one of the parents and the child could lead to different ratings despite both parents being observers of the same symptoms. While mothers, traditionally, due to specialization in housework over market work, have had a 
stronger attachment to the child, this is changing in dual earner societies as fathers participate more in child-rearing. Indeed time diary studies comparing the mid-60's to the late-90's show that married fathers participate much more actively in routine and developmental child care activities than they did in the past (Sayer, Bianchi and Robinson 2004). For Denmark, comparing time-use data between 1987 to 2008, researchers found that Danish fathers rank second among European fathers (after Swedish fathers) in terms of the amount of time spent on children aged 7-17, and that they increased the daily time spent with their children by 15 minutes between 1987 and 2008 (Rockwool Foundation Research Unit, 2010 for Denmark).

In the following section, we describe how we operationalize the theoretical concepts highlighted above and define determinants of informant discrepancies in the data.

\section{Data}

The data we use is drawn from a rich survey on children's outcomes, modes of care and parental background information, known as the Danish Longitudinal Survey of Children (DALSC). The DALSC is a repeated survey of the primary parent of, initially, roughly 6,000 children born between 15 September and 31 October 1995. The first wave took place when the children were 6 months old (1996), the second when they were around 3 (1999), the third at age 7 (2003) when the children are expected to have started first grade (age 7 in Denmark), and the fourth at age 11 (2007). The fathers of these children were surveyed separately in 1999 and 2007.

For the purpose of this study, we mainly focus on the last wave of the survey, as it is the only one containing both parents' reports of some of the child outcomes. We only include those "intact" households in which the male respondent is the biological father, as communication issues among parents are less of a concern for this kind of families. Moreover, children with strong dyslexia, vision impairment or hearing, speech handicap or other handicap are excluded 
from our analysis. ${ }^{1}$ The survey data have been merged to administrative registers holding information on parents' educational attainment, labor market status and income for the years 2000-2006 and the number of psychiatric diagnoses for 2005. Self-reported child care enrollment status is measured in 1999 and child outcomes are all recorded in 2007, when the child is expected to be in fifth grade.

To explicitly test whether informant discrepancies are explained by the theoretical hypothesis outlined in section II, the following groups of explanatory variables are selected for our empirical analysis. First, we measure parent psychopathology by including a dummy variable indicating whether the mother suffered from post-partum depression, whether parents argue every day or couple of times a week on a number of relevant topics, such as financial matters, bringing up the child and sharing the workload of the daily housework, and a count measure of all psychological symptoms for which the parent reports to have recently consulted a doctor including anxiety, nervous tension, depression, sleeping problems and stress. The latter variable is alternatively measured as the average number of psychiatric symptoms for which the parent has been diagnosed in $2005 .^{2}$

Second, we add a number of variables proxying for the social ties between the parent and the child: i) whether the parent has a very close relationship with the child; ii) whether the parent spends time with the child engaging in activities $^{3}$ on a daily basis; iii) the parent labor market experience in 2006; iv) whether the father is the breadwinner ${ }^{4}$; v) whether the child was enrolled in a municipality provided daycare program at age 3 and vi) the hours of non-parental care. Third, to control for differences in perspectives arising from cultural differences and to

\footnotetext{
${ }^{1}$ We check for potential sample selection bias by comparing means of all variable across both samples, as discussed later in the same section. Moreover, including these specific cases does not substantially change our estimation results. The latter are available on request from the authors.

2 The number of psychiatric diagnoses has been collected according to the ICD-10 manual and refers to the following disorders: organic and symptomatic mental disorders; schizophrenia; mood disorders; neurotic, stressrelated and somatoform disorders; behavioral syndromes associated with physiological disturbances and physical factors and disorders of adult personality and behavior.

${ }^{3}$ The following activities are included in the survey: cooking, reading, doing homework and playing together.

${ }^{4}$ For the father to be the breadwinner, two conditions need to be fulfilled. Both his average labor market experience and his income over the period 2000-2006 are higher than those of the mother.
} 
proxy for social desirability issues, we include information about the parental socio-economic background, like household disposable income (averaged over the period 2000-2006), parents' educational level, whether parents have different educational and cultural/ethnic background. We also consider the child gender, the number of older sibling and whether the mother is at least 3 years younger than the father.

Table 1 reports the main descriptive statistics of all the variables used in our empirical analysis, separately by child gender and by whether disabled kids and non-intact households are included or not in the sample. Aside from the outcome variables, means of the explanatory factors - parental psychopathology, social ties or parental socioeconomic background - are roughly similar by child gender and by the type of sample, although a slightly larger share of mothers of girls report spending quality time with the child compared to mothers of boys $(89.5 \%$ vs. $85 \%)$. Another difference is that $92 \%$ of boys were in municipality provided care at age 3 compared to $85 \%$ of girls. Furthermore, in the non-intact families sample, parents tend to report more symptoms, fathers are less close to the child and spend less quality time with the child, and fathers and mothers have less work experience. Boys are more likely than girls to have a psychiatric diagnosis at age 9 (4.8\% vs. $1.3 \%)$.

Our first outcome measures are the mother and the father versions of the Strengths and Difficulties Questionnaire (SDQ), which is a 25-item instrument for assessing social, emotional and behavioral functioning, that has become a widely used research instrument for the mental health of children (Goodman 1997). A closely related measure, the Behavior Problem Index, is used in Cunha and Heckman (2008) to investigate the production of cognitive and non-cognitive skills. Answers to the 25 questions are grouped into five scales of five items each, generating scores from 0 to 10 for emotional symptoms, conduct problems, hyperactivity, peer problems and prosocial behavior. Excluding the prosocial behavior, the five items in each subscale are then summed up to the total difficulties scores ranging from 0 to 40 . Subtracting the mother ratings from the father ratings creates difference scores used to explore levels of parental agreement about the level of child mental problems. 
From Table 1 we can see that mothers tend to report worse behavior than fathers (positive SDQ difference), with no difference according to child gender. In absolute value, the average difference in ratings is about 3 points, which is quite large considering the SDQ scale. Table 2 presents the correlations between the two informants' ratings of behavioral problems. There is clearly evidence of dissimilarity of both parents' evaluations, given that cross-respondent correlations are all below 0.7. Note that the agreement tends to be greater about externalizing behaviors, e.g. hyperactivity and conduct problems, compared to internalizing behaviors, e.g. emotional and prosocial problems. As we mentioned in section II, internalizing problems are more difficult to observe and are less likely to be disruptive to the family functioning and, therefore, less likely to attract the attention of both parents. This is also evident in Figure 1, showing the distributions of both parents' SDQ evaluations. The second set of outcomes measure (reported) child school performance. Both parents are asked a couple of questions about the child school performance: "How well do you think your child fares academically?" and "Does your child like doing homework?". The former question is also asked for each subject separately, i.e. Danish, Math, Science and English. ${ }^{5}$ In Table 1, we saw that fathers tended to report worse academic performance than mothers (negative difference). This corresponds to an average difference of 0.4 , in absolute value. Fathers are also more likely to negatively answer to the question concerning homework (positive difference). As in the case of the SDQ ratings, there is strong evidence of dissimilarity between mother and father evaluations in the pairwise correlations between respondents' evaluations, shown in Table 3. As we can see from Figures 2 and 3, mothers are more likely to rate their child academic performance as "very well" and to declare that their child likes doing homework compared to fathers.

\footnotetext{
${ }^{5}$ Responses range from "Very well" (coded 1) through "Badly" (coded 5).
} 


\section{Methodology}

\section{IV.1 Parental discrepancies}

As suggested in Johnston et al. (2010), our point of departure in exploring the between parent differences in reports of child outcomes, $\Delta \mathrm{CO}_{\mathrm{i}}$, is to estimate a standard linear regression $\operatorname{model}^{6}$ :

$$
\Delta \text { CO }_{i}=\beta_{p} \text { PARENTAL_PSYCHO }_{i}+\beta_{\text {St }} \text { STIES }_{i}+\beta_{S} \text { SOCIO }_{i}+\beta_{\mathrm{o}} \mathrm{OTHER}_{\mathrm{i}}+\varepsilon_{\mathrm{i}},
$$

where, PARENTAL_PSYCHO $i$ is the information about the psychopathology of parents of the $i^{\text {th }}$ child, $S T I E S_{i}$ is a set of proxies for social ties, $S O C I O_{i}$ is a vector of parental socioeconomic characteristics and $O T H E R_{i}$ include additional controls such as child gender, the number of older siblings and whether the mother is at least 3 years younger than father. ${ }^{7}$ The coefficients generally indicate how large the contribution is of the variables included in the specification in explaining the differences between the mother's and the father's ratings. A positive (negative) coefficient for maternal psychopathology, for example, indicates that a mother with more symptoms tends to assign her child higher (lower) scores relative to the father. This is the reverse for the father, where a positive (negative) coefficient for paternal psychopathology would indicate that fathers with more symptoms tend to rate their children lower (higher) scores relative to the mother. It should be noted that in such a "change" model any unobservable common to households (shared tastes, common views on upbringing, etc.), which could be correlated with parental reporting and its observed determinants is differenced out. As an additional attempt to partly address the issue of unobserved heterogeneity, we also estimate equation (1) by using quantile regression techniques. The coefficients obtained from

\footnotetext{
${ }^{6}$ Similar results, which are available on request from the authors, are obtained by estimating a linear heteroskedastic regression model, where the variance is modeled as a function of all the explanatory variables included in equation (1).

${ }^{7}$ Given that parental perception of child behavior and school performance has been found to vary substantially by gender in the previous literature (Kolko and Kazdin 1993; Duhig et al. 2000), we have also estimated equation (1) separately for girls and boys. Results are very similar to the ones reported in the paper and are available on request from the authors.
} 
the latter can in fact be interpreted in terms of latent characteristics, i.e. a sort of latent "propensity" to behave differently along the distribution of parental discrepancies, which are implicitly indexed by each quantile (Doksum 1974).

\section{IV.2 Generalized ordered probit model}

A complementary way to assess whether certain parents' characteristics affect their perceptions of the child outcomes is to test the presence of systematic reporting heterogeneity (Bago d'Uva et al. 2007; Lindeboom and van Doorslaer 2004). This can be done by estimating a generalized ordered probit where the thresholds are a function of the respondent characteristics (Kerhofs and Lindeboom 1995; Lindeboom and Van Doorslaer 2004). This approach considers a sufficiently comprehensive set of proxy indicators of the child outcome that absorb all of the association between true child outcome and the covariates. Consequently, conditional on those indicators, any relationship between the latter and reported child outcome is attributable to reporting behavior. Assume that the underlying true child outcome $\mathrm{CO}_{\mathrm{i}}$ can be expressed as:

$$
\begin{gathered}
C O_{i}^{*}=X_{i} \beta+\xi_{i} \\
C O_{i}=j \text { if } \tau_{i}^{j-1}<C O_{i}^{*} \leq \tau_{i}^{j-1}, \quad j=1,2,3 . \quad \text { (2) }
\end{gathered}
$$

where the matrix $X_{i}$ includes informants' characteristics, as the socio-economic background, the level of psychopathology and the social ties with the assessed child, while $\mathrm{CO}_{i}$ is the parental categorical assessment of the child outcomes. In the presence of systematic reporting heterogeneity, the thresholds $\tau$ are not constant and differ with respondents' characteristics, as follows:

$$
\begin{gathered}
\tau_{i}^{1}=\gamma^{1} X_{i} \\
\tau_{i}^{j}=\tau_{i}^{j-1}+\exp \left(\gamma^{j} X_{i}\right)
\end{gathered}
$$


With information only about $C O_{i}$ and $\mathrm{X}$, it is not possible to separately identify $\gamma^{j}$ and $\beta$. However, the identification of $\gamma^{j}$ is achieved with additional information on true child outcomes, $\mathrm{CO}_{i}^{*}$, via proxy indicators. Then, a model of the relationship between true child outcomes $\mathrm{CO}_{i}^{*}$, objectively measured child outcomes $\mathrm{CO}_{i}^{O}$, reported child outcomes $\mathrm{CO}_{i}$ and covariates $X_{i}$ is given by (2), (3) and:

$$
C O_{i}^{*}=g\left(C O_{i}^{O}\right)+\eta_{i}
$$

Parents' categorical assessments, $\mathrm{CO}_{i}$, ordered on a given scale, are only available for the child school performance ${ }^{8}$, we therefore do not apply the generalized ordered probit model to child SDQ scores, as reported by parents. We then use the scores from both the Children's Problem Solving (CHIPS TEST) and the language test, as objective measures of the child cognitive functioning, $\mathrm{CO}_{i}^{O}$.

\section{IV.3 Linear factor model}

After having investigated response heterogeneity, we finally assess which parent's assessment is closest to the objective measures of a specific item of child functioning. In the present study, objective measures of both the child mental and academic functioning are available, i.e. the number of psychiatric diagnoses ${ }^{10}$, CHIPS scores and language scores.

\footnotetext{
${ }^{8}$ Child school performance is measured using parents' assessments of how well their child fares academically. Relatively few replied "average", "not so well" and "badly" so we combined these three categories together and proceeded with 3 categories: (1) very well, (2) well, (3) average, not so well and badly. To ease and achieve the convergence of the likelihood function, we model only the first threshold (the one of the category "very well") as a function of covariates, $\mathrm{X}$, and we normalize the second and third thresholds to a constant.

${ }^{9}$ In the 2007 wave, the children were administered both a language test and a test of logical thinking (the Children's Problem Solving or CHIPS test). The CHIPS test involved completing a series of number sequences. Both tests were composed as a set of multiple choice questions. The maximum score obtainable on the language test was 34 points; on the CHIPS test 40 points.

${ }^{10}$ Beside the disorders described in footnote, we also include the following child-specific psychiatric diagnoses: specific developmental disorders of speech and language, specific developmental disorder of scholastic skills, specific developmental disorder of motor function, mixed specific developmental disorders, pervasive developmental disorders, other disorders of psychological development, unspecified disorder of psychological
} 
Therefore, we estimate the following linear factor model:

$$
\left\{\begin{array}{c}
C_{i}=\alpha_{c}+\lambda_{1 c} * m_{A C A}+\lambda_{2 c} * f_{A C A}+u_{i c} \\
L_{i}=\alpha_{l}+\lambda_{3 l} * m_{A C A}+\lambda_{4 l} * f_{A C A}+u_{i l} \\
D_{i}=\alpha_{d}+\lambda_{5 d} * m_{S D Q}+\lambda_{6 d} * f_{S D Q}+u_{i d}
\end{array}\right.
$$

where, $C_{i}, L_{i}$ and $D_{i}$ are respectively the CHIPS scores, the language scores and the number of psychiatric diagnoses, $m_{S D Q}$ and $m_{A C A}$ are the mother's assessments of respectively the child behavior and academic performance, $f_{S D Q}$ and $f_{A C A}$ are the respective father's assessments, and $\lambda$ represents the vector of factor loadings (Borghans et al. 2008). The terms $u_{i c}$ and $u_{i l}$ are assumed to be jointly normal with zero means and variance matrix $\Sigma_{C L}$. The factor model (5) can be computed using maximum likelihood estimation and captures the notion that parental assessments are imperfect measures of true underlying child functioning, proxied by the objective measures of academic performance. A purely misreported assessment of child functioning would be associated with a zero $\lambda$ coefficient.

\section{Results}

This section provides a discussion of all the results obtained from the empirical analysis. The first set of results tests the theoretical hypothesis outlined in section II, by looking at whether informants' discrepancies of child behavioral and academic outcomes correlate systematically with informants' characteristics. We then study and examine the role of response heterogeneity in parents' assessments of the child academic performance. The empirical analysis concludes by assessing the relative importance of the mother's and the father's assessments in explaining child functioning, to investigate whether one parent is systematically a better informant of children's outcomes.

development, hyperkinetic disorders, conduct disorders, mixed disorders of conduct and emotions, emotional disorders with onset specific to childhood, disorders of social functioning with onset specific to childhood and adolescence, tic disorders, other behavioral and emotional disorders, unspecified mental disorder and problems concerning social environment. 


\section{V.1 Correlates of informants' discrepancies}

Table 4 shows the estimates of equation (1) for parents' differences in ratings of child behavior measured by the total SDQ scores. Eleven different models have been estimated. The first four columns include results from the most parsimonious specification, including information about parental psychopathology and child gender together with the number of older siblings, to the exhaustive one, adding respectively the variables related to social ties (column 2), those proxying parental socioeconomic background (column 3) and using an alternative measure of parental psychopathology (column 4). Comparison of the first four columns shows that there are no large differences between the different specifications. ${ }^{11}$ First, discrepancies in the total difficulties score of child mental problems are positively correlated with maternal psychopathology, no matter whether measured by a count of all psychological symptoms for which the mother has recently consulted a doctor or by the number of psychiatric diagnoses. Hence, mothers with poor mental health rate their children more harshly than fathers do. More specifically, an additional self-reported symptom is associated with a 0.056 standard deviation increase in the difference between parental ratings. ${ }^{12}$ This result is consistent with the hypothesis that mothers' disorders are distorting variables in mothers' reports on child behavior. The same hypothesis does not hold for fathers, as their symptoms, self-reported or objectively measured, are not statistically correlated with the level of disagreement between parents. However, fathers who declare themselves as often having arguments with their spouses tend to report more disorders compared to mothers, and the same is found for mothers' perception of arguments.

The qualitative dimension of social ties, i.e. the quality of the relationship between parent and child, works also symmetrically for mothers and fathers. Mothers with a close relationship

\footnotetext{
${ }^{11}$ Several diagnostics indicates that multicollinearity is not a problem in our estimations. The variance inflation factor (VIF) is, for example, around 1.5 in the most complete specification, much below the threshold suggested by Allison (1999).

${ }^{12}$ This result is obtained by standardizing the dependent variable. As the mean and the standard deviation of the dependent variable are respectively 0.651 and 3.705, an additional symptom is associated with an 8 percent increase in the reporting gap between parents. Not all the y-standardized coefficients are reported in the paper, but all are available on request from the authors.
} 
with the child seem to downplay child behavioral problems compared to fathers, as clearly indicated by a negative correlation between a close mother-child relationship and the total SDQ scores. A close mother-child relationship produces, on average, a 0.047 standard deviation decrease in the difference between the mother's and the father's ratings. This result may be consistent with the hypothesis that a closer social attachment between mothers and their children leads to more lenient ratings of child behavior. Leniency can be explained by either the mother's social preferences being closer toward the evaluated child or by social desirability issues, i.e. the tendency to deny or minimize socially undesirable symptoms. The same is found for fathers: having more familiarity with their child lead to them to report fewer symptoms compared to mothers (positive coefficient, which corresponds to 0.076 standard deviation increase). Thus, qualitative aspects of parental involvement may lead to greater leniency towards child behavioral problems. Another possible interpretation of the previous results could be that the parent, who is closer to her/his child, more accurately gauges her/his child's behavioral problems. All in all, these results also indicate that parental involvement has strong and symmetric effects on parental ratings of child behavior. This is not, however, confirmed by other proxies of parental involvement: for example, the dummies of whether the mother or the father spends quality time with their child are never statistically significant. Furthermore, while the effect of the child being cared for in a municipality provided daycare program at age 3 is positive (i.e. mothers rating behavior worse than fathers), it is imprecisely estimated, and hours of non-parental care, though statistically significant, are not substantially related to the degree of parental disagreement, as indicated by the magnitude of the coefficient.

Our results also indicate that none of the variables related to the parents' socio-economic status, such as differences in educational and ethnic background, is significantly associated with the level of parental discrepancies. Finally, we generally do not find that the gender of the child, the number of older siblings or the age difference within the couple influence parental discrepancies.

We, then proceed by separately adding to the most complete specification, two interaction 
terms to check whether the proxies for social ties have heterogeneous associations with parental discrepancies according to the child gender. More specifically, the first interaction is between child gender and whether the mother or the father has a close relationship with the child (column 5) while the second one is between the child gender and whether the father is the breadwinner within the household (column 6). None of the interactions is statistically significant, dismissing the surmise that mothers and fathers who have a close relationship with the child may differently perceive the behavior of their child or gather different amounts of information about the child, depending on child gender.

Next, we estimate equation (1) by quantile regression methods to get a more complete picture of how the variables included in the main specification are associated with different quantiles of the conditional parental reporting gap distribution. As mentioned in the previous section, the propensity to behave differently along the distribution of the dependent variable can be interpreted as a natural measurement of a latent characteristic correlated with both the dependent and explanatory variables. Quantile regressions are estimated at three different quantiles $(0.25 ; 0.50 ; 0.75)$ and the results are respectively reported in columns 7,8 , and 9 of table 4. To avoid the bandwidth choice required by the kernel estimator, we decided to use a bootstrap estimator for the standard errors. For each quantile estimator, 500 bootstrap replications are performed and the standard deviations are computed. The ordinary least squares (column 3 ) are fairly similar to the $50^{\text {th }}$ quantile (median) regression (column 8 ), but the varying nature of the estimates at the other quantiles provides an interesting picture of how the distribution of informant discrepancies is related to the covariates. Note that mother symptoms, mother perception of arguments and whether the mother has a close relationship with the child are not statistically significant at the $25^{\text {th }}$ quantile. However, the magnitude and the statistical significance of the estimates for these variables slightly improve when moving to higher quantiles. A close mother-child relationship, for example, associates with a 0.034 and a 0.053 standard deviation decrease in the mother's ratings compared to the father's ones, respectively at the $50^{\text {th }}$ and the $75^{\text {th }}$ quantiles. On the other hand, the estimates for whether the father has a close relationship with the child are always statistically significant but decrease monotonically from the lower quantiles to the higher quantiles (from 0.065 to 0.039 standard 
deviation increase in the father's ratings compared to those of the mother). This means that the greater discrepancy associated with the father relationship with the child seems to be more evident at lower quantiles of the discrepancies distribution. The opposite result holds for the mother-child relationship dummy, i.e. the discrepancy for mothers who are closer to their children seems to increase the bigger the gap in parental rating. One interpretation of this finding could be that mother closeness has a mitigating effect i.e. when parental differences in assessments are large, whereas father closeness has a reinforcing effect.

In the last two columns of Table 4, we finally check the robustness of our results by looking at how the parents' characteristics correlate with the probability that the maternal assessments are at least two points higher (column 10) or lower (column 11) than the paternal ones. We find that these probabilities are respectively positively and negatively associated with maternal psychopathology, confirming that mothers with poor mental health tend to overplay their child mental problems. The opposite is found for the variable proxying qualitative aspects of parental involvement: having a close relationship with the child is negatively (positively) correlated with the probability that the mother reports more (fewer) symptoms than the father, and likewise for the father.

We then proceed by checking whether the associations between informants' characteristics and informants' discrepancies vary between item-specific SDQ scores. It is, in fact, reasonable to expect that some informant characteristics are more strongly correlated with the ratings of internalizing behaviors than with the ratings of externalizing behaviors and vice versa. Social ties, for example, may matter less for the ratings of hyperactivity and conduct problems, which are easier to observe, compared to emotional problems ${ }^{13}$. Results included in Table 5, however, do not support this hypothesis, as the coefficients do not change much across SDQ items. The dummies of whether the mother or the father has a close relationship with the child, the mother symptoms and both parents' perceptions of familial arguments are overall

\footnotetext{
${ }^{13}$ Recall that prosocial behavior is a positive behavioral trait, hence its coefficient is of the opposite sign vis-à-vis the other items.
} 
significantly associated with the SDQ sub-items as they were for overall SDQ. Interestingly, the symmetric associations between parental perceptions of arguments and child behavior are strongest for hyperactivity problems, i.e. externalizing disorders, but also prosocial behavior, which is presumably also easier to observe. Moreover, we find that the magnitudes of the effects of mother social ties are slightly higher for the conduct and hyperactivity problems compared to the emotional ones, the reverse of what was hypothesized. Whereas for fathers, we see that the effect of social ties or closeness is highest for prosocial behavior and hyperactivity. Thus, both mothers and fathers who are close to their children are more likely to report significantly less hyperactivity. For mothers with mental symptoms, not surprisingly, emotional problems in children tend to be reported more. Unlike in Table 4, child gender plays a role in parental discrepancies for two of the sub-items of SDQ - mothers of girls report significantly more conduct problems but significantly fewer hyperactivity problems than fathers.

Table 6 includes results related to the differences in parental reporting of academic performance. The first four columns successively add groups of covariates to the main specification, columns 5 and 6 include a few interactions with child gender while the last two are based on the probability that the mother's assessments are respectively worse (better) than those of the father. As mentioned in section III, child academic performance is proxied by the respondent's perception of how well the child fares academically, recalling that the perception score ranges from 1 ("Very well") to 5 ("Badly") so that a positive coefficient means that mothers rate academic performance harsher than fathers. We see that a mother's psychopathology (number of reported symptoms or psychiatric diagnoses) negatively affects her ratings of child academic performance in the fuller specifications. Specifically, an additional reported symptom correlates with a 0.041 standard deviation increase in the difference between mother's and father's ratings. ${ }^{14}$ Paternal psychopathology is, however, not correlated with the pairwise discrepancies. Social ties play a relevant role here too. A mother

\footnotetext{
${ }^{14}$ As the mean and the standard deviation of the dependent variable are respectively -0.040 and 0.673 , an additional symptom is associated with a 100 percent increase in the reporting gap between parents.
} 
who has a close relationship with the child is more likely to assess positively her child's academic performance than the father of the same child. The same holds for the father, who seems to judge his child more positively compared to the mother the closer he is to it. A mother (father) close relationship leads to nearly a 0.050 standard deviation decrease (increase) in the difference between both parents' ratings. As in case of SDQ discrepancies, we see that the quality of the relationship with the child seems to enhance the leniency of the parent's ratings. Of course another interpretation of these results could be that parents can more accurately gauge their children's ability, the closer they are to them. Looking at the probability that the mother assess the child academic performance worse or better than the father provides qualitatively similar results. Furthermore, parental assessments of academic performance disaggregated by subject and of whether the child likes doing her/his homework corroborate these findings, especially strong for Science but also for the other subjects (see table 7). Mothers of girls are significantly more likely to report lower homework likeability than fathers.

The fact that these results are all robust across different items of the child functioning assures to some extent us that the estimated and discussed associations are not purely driven by spurious correlations and simultaneity issues. We now turn to the issue of whether certain characteristics, like for example the social ties, affect indeed the thresholds by which parents assess the child academic performance.

\section{V.2 Generalized ordered probit results}

Table 8 reports results from the generalized ordered probit, as reported in equations (2)-(4), estimated separately for each parent. ${ }^{15}$ Not surprisingly, objective measures of academic performance, measured by scores from the CHIPS and the language tests, are positively correlated with both parents' assessment of their child overall academic performance ${ }^{16}$, as

\footnotetext{
${ }^{15} \mathrm{We}$ are not able to report results by child gender as models separately estimated for boys and girls did not converge.

${ }^{16}$ Note that the dependent variable ranges from "Very well" (coded 1) through "Badly" (coded 5). Hence a negative coefficient estimated on the objective scores is interpreted as a positive correlation.
} 
shown in the first two columns. In the threshold equation we control for some of the covariates included in equation (1), used to explain informants' discrepancies. For both parents, the "close relationship" dummy enters with a positive sign and significantly in the equation for the first threshold parameter, corresponding to the category "very good". This means that parents with a close relationship with their child have a lower standard of what constitutes a very good academic performance compared to other parents. This is consistent the hypothesis that qualitative aspects of parental involvement can negatively affect the accuracy of ratings and favor more lenient assessments. Combined with the results reported in the previous subsection, we can argue that the "leniency" effect of a close relationship are stronger than the "awareness" effect and that parents do not necessarily more accurately gauge their children's ability, the closer they are to them. However, we cannot test whether this is the case, when parents have to assess their child mental functioning. Estimation of a generalized ordered probit using a parent's version of the SDQ scores is not feasible, as it is not a categorical variable ordered on a predefined scale as is the assessment of school performance.

Another interesting result is that parents who declare to have often arguments have a lower initial threshold, i.e. they tend to rate their child's performance as harsher than otherwise comparable parents. As found in the analysis of the correlates of parental discrepancies, chronic parental conflicts may work as a distorting variable in parent reports on child academic performance, in that conflicts are associated with reporting more negative assessments. Finally mothers having other older children than the assessed child are found to have a higher standard of when to cross the first threshold limit for the child academic performance. More experienced mothers are therefore more likely to judge their child more harshly than otherwise comparable less experienced mothers. As a robustness check, we estimate our generalized ordered probit model by using the parental assessments of the child academic performance in Math and in Danish, as these might be more directly related respectively to the Chips and Language scores compared to the general assessments. As reported in the remaining columns of Table 8 , the results obtained from the subject-specific assessments are in line with those from the general assessments. 


\section{V.3 Linear factor model results}

Finally, in this section, we assess the relative importance of the mother's and the father's assessments in explaining an objective measure of the child functioning, measured in our case by the CHIPS, the language scores and the number of psychiatric diagnoses. The parameter estimates of the linear factor model (5) are given in table 9. Coefficients are also reported in standard deviation units, i.e. beta coefficients, to be able to compare the relative contributions of factors, thereby easing the comparison across magnitudes. Moreover, statistical tests of the equality of the factor loadings across parents' ratings are included at the bottom of table 9 . The vector of factor loadings, $\lambda$, in the CHIPS scores equation, as reported in the first column, indicates that both parents are given fairly similar weight in explaining the child academic performance, objectively measured. Hypothesis testing reveals also that the loadings associated with the mother's assessments are not statistically different from the ones associated with the father's assessments. This is also the case for the language scores and the number of psychiatric diagnoses, where the mother's assessments seem to be as relevant as those of the father's in explaining these objective measures. Overall the evidence provided by the linear factor model allows us to dismiss the surmise that mothers are the most accurate in reporting and assessing child functioning, as suggested in Treutler and Epkins (2003).

As a robustness check, we then check whether this assumption holds using both parents' assessments of the child's academic performance in Math and Danish, instead of the general ones. Results reported in the second column indicate that the mother's assessments do not receive a higher and statistically different weight in explaining child school functioning compared to those of the father's. The same holds for the discrete factor model separately estimated by the child gender, as we can see in the last two columns of Table 9. 


\section{Conclusions}

This study investigates the degree of correspondence between parents' reports on child cognitive and non-cognitive outcomes using the last wave of the Danish Longitudinal Survey of Children (DALSC). Descriptive analysis provides clear evidence of dissimilarity in parent evaluations of child behavior, with higher disagreement levels found for internalizing behaviors, e.g. emotional and prosocial problems. High levels of discrepancies are also found where assessments of child academic performance are concerned.

Once discrepancies are detected, we analyze whether they are driven by noisy evaluations or by systematic bias, focusing on the role of informants' characteristics. A few systematic factors are found to drive the differences in assessments. Our results are consistent with the hypothesis that parental psychopathology measured as mothers' mental disorders, are distorting variables in their reports of child functioning. The relationship between the parent and the child which we operationalize as qualitative aspects of the parent-child relationship are correlated with discrepancies of both cognitive and non-cognitive child ratings, with aspects of parental involvement having symmetric effects on parental ratings. Our results on response heterogeneity enable us to conclude that a close relationship with the child seems to enhance the leniency rather than the accuracy of the parent's ratings.

Estimates from a linear factor model finally reveal that the mother is not a better informant of child functioning compared to the father. This result reflects the growing role of fathers in their children's lives as seen in many countries today, and it calls into question the practice of clinicians or teachers to rely primarily on the mother as the better informant.

These findings give important input to child policy makers and practitioners because incorrect assessments can lead to an inefficient level of investments that can have far-reaching consequences for children's future human capital development. 


\section{References}

Achenbach, Thomas M., Stephanie H. McConaughy, and Catherine T. Howell. 1987. "Child/adolescent behavioral and emotional problems: Implications of cross-informant correlations for situational specificity." Psychological Bulletin 101:213-232.

Allison, Paul D. 1999. Multiple Regression: a primer, page 142. Pine Forge Press: Thousand Oaks, C.A.

Almond, Douglas, and Janet Currie. 2010. "Human Capital Development Before Five." Chapter 15 in Handbook of Labor Economics, Volume 4, ed. David Card and Orley Ashenfelter, Amsterdam: Elsevier Science B.V.

Bago d'Uva, Teresa, Eddy van Doorslaer, Maarten Lindeboom, and Owen O'Donnell. 2007.

"Does reporting heterogeneity bias the measurement of health disparities?" Health Economics 17:351-375.

Baker, Michael, Jonathan Gruber and Kevin Milligan. 2008. "Universal Child-Care, Maternal Labor Supply, and Family Well-Being.” Journal of Public Economics, Vol. 116: 709745.

Baker, Michael, Mark Stabile, and Catherine Deri. 2004. "What do self-reported objective measures of health measure?" Journal of Human Resources 39:1067-1093.

Becker, Gary, S. and Nigel Tomes. 1986. "Human Capital and the Rise and Fall of Families." Journal of Labor Economics 4(3): S1-39, July.

Bernal, Raquel, and Michael P. Keane. 2011. "Child Care Choices and Children's Cognitive Achievements: The Case of Single Mothers." Journal of Labor Economics 29: 459512.

Blanden Jo, Paul Gregg, and Lindsey Macmillan. 2006. "Explaining Intergenerational Income Persistence: Non-cognitive Skills, Ability and Education." CMPO Working Paper Series 06/146, Department of Economics, University of Bristol, UK.

Blau, David, and Janet Currie. 2008. "Efficient Provision of High-Quality Early Child- hood Education: Does the Private Sector or Public Sector Do It Best?” CESifo DICE Report, Ifo Institute for Economic Research at the University of Munich, vol. 6(2).

Borghans, Lex, Angela Lee Duckworth, James J. Heckman and Bas ter Weel, 2008. "The Economics and Psychology of Personality Traits. " Journal of Human Resources 
43(4):973-1059.

Brown, Jonathan D., Lawrence S. Wissow, Anne Gadomski, Ciara Zachary, Edward Bartlett, and Ivor Horn. 2006. "Parent and teacher mental health ratings of children using primary care services: Inter-rater agreement and implications for mental health screening." Academic Pediatrics 6:347-351.

Case Anne, Angela Fertig, and Christina Paxson. 2005. "The Lasting Impact of Childhood Health and Circumstance." Journal of Health Economics 24:365-389.

Case, Anne, Darren Lubotsky, and Christina Paxson. 2002. "Economic status and health in childhood: The origin of the gradient." American Economic Review 92:1308-1334.

Currie, Janet, and Mark Stabile. 2003. "Socioeconomic status and child health: Why is the relationship stronger for older children?” American Economic Review 93:1813-1823.

Currie, Alison, Michael A. Shields, and Stephen Wheatley Price. 2007. "The child health/family income gradient: Evidence from England." Journal of Health Economics 26:213-232.

Cunha, Flavio, and James J. Heckman. 2008. "Formulating, Identifying and Estimating the Technology of Cognitive and Noncognitive Skill Formation”. Journal of Human Resources vol. 43: 738-782.

Datta Gupta, Nabanita, and Marianne Simonsen. 2010. "Non-cognitive Child Outcomes and Universal High Quality Child Care.” Journal of Public Economics 94:30-43.

Datta Gupta, Nabanita, and Marianne Simonsen. 2011. "Effects of Type of Non-parental Child Care on Pre-teen Skills and Risky Behavior." Economics Letters 116 (3): 622-625.

Doksum, Kjell. 1974. "Empirical probability plots and statistical inference for nonlinear models in the two sample case." Annals of Statistics, 2: 267-77.

Duhig, Amy M., Kimberly Renk, Monica K. Epstein, and Vicky Phares. 2000. "Interparental agreement on internalizing, externalizing, and total behavior problems: A metaanalysis." Clinical Psychology: Science and Practice 7:435-453.

Fisher, Robert J. 1993. "Social desirability bias and the validity of indirect questioning." Journal of Consumer Research 20(2): 303-15.

Goodman, Robert. 1997. "The Strengths and Difficulties Questionnaire: A Research Note.” Journal of Child Psychology and Psychiatry 38:581-586. 
Havnes, Tarjei, and Magne Mogstad. 2011. "No Child Left Behind: Subsidized Child Care and Children's Long-Run Outcomes." American Economic Journal: Economic Policy 3:97-129.

Jensen, Peter S., Stephen N. Xenakis, Harry Davis, and James Degroot. 1988. "Child psychopathology rating scales and interrater agreement: II. Child and family characteristics." Journal of the American Academy of Child and Adolescent Psychiatry 27:451-461.

Johnston, David W, Carol Propper, Stephen E. Pudney, and Michael A. Shields. 2010. "Is there an income gradient in child health? It depends whom you ask. "Working Papers 5283, Imperial College, London, Imperial College Business School.

Kerkhofs, Marcel and Maarten Lindeboom. 1995. "Subjective Health Measures and State Dependent Reporting Errors." Health Economics, 4: 221-235.

Krain, Amy L., and Philip C. Kendall. 2000. "The role of parental emotional distress in parent report of child anxiety." Journal of Clinical Child Psychology 29:328-335.

Kolko, David J., and Alan E. Kazdin. 1993. "Emotional/behavioral problems in clinic and nonclinic children: Correspondence among child, parent and teacher reports." Journal of Child Psychology and Psychiatry 34:991-1006.

Lindeboom, Maarten, and Eddy van Doorslaer. 2004. "Cut-point shift and index shift in selfreported health." Journal of Health Economics 23:1083-1099.

McLeod, Jane D., and Karen Kaiser. 2004. "Childhood Emotional and Behavioral Problems and Educational Attainment." American Sociological Review 69:636-658.

Prendergast, Canice. 2002. "Consumers and Agency Problems.” The Economic Journal 112: 34-51.

Prendergast, Canice, and Robert Topel. 1996. "Favoritism in organizations." Journal of Political Economy 104:958-978.

Presser, Stanley and Linda Stinson. 1998. "Data collection mode and social desirability bias in self reported religious attendance." American Sociological Review 63(2): 137-45.

Renk, Kimberly, Vicky Phares, and James Epps. 1999. "The relationship between parental anger and behavior problems in children and adolescents." Journal of Family Psychology 13:209-227. 
Rockwool Foundation Research Unit. 2010. "Parents are spending an increasing amount of time on their children." News from the Rockwood Foundation Research Unit, February, 2011.

Sayer, Liana C., Bianchi, Suzanne M. and John P. Robinson. 2004. “Are parents investing less in children? Trends in mothers' and fathers' time with children." American Journal of Sociology,110(1):1-43.

Silverman, Wendy K., and Brian Rabian. 1995. "Test-retest reliability of DSM-III-R anxiety disorders symptoms using the Anxiety Disorders Interview Schedule for Children." Journal of Anxiety Disorders 9:139-150.

Treutler, Christina M., and Catherine C. Epkins. 2003. "Are discrepancies among child, mother, and father reports on children's behavior related to parents' psychological symptoms and aspects of parent-child relationships?" Journal of Abnormal Child Psychology 31:13-27.

Tversky, Barbara, and Elizabeth J. Marsh. 2000. "Biased retellings of events yield biased memories." Cognitive Psychology 40:1-38.

Youngstrom, Eric A., Carroll Izard, and Brian Ackerman. 1999. "Disphoria-related bias in maternal ratings of children." Journal of Consulting and Clinical Psychology 67: 905916.

Youngstrom, Eric A., Robert L. Findling, and Joseph R. Calabrese. 2003. "Who are the comorbid adolescents? Agreement between psychiatric diagnosis, youth, parent, and teacher report." Journal of Abnormal Child Psychology 31:231-245. 
Figure 1: Distributions of SDQ scores
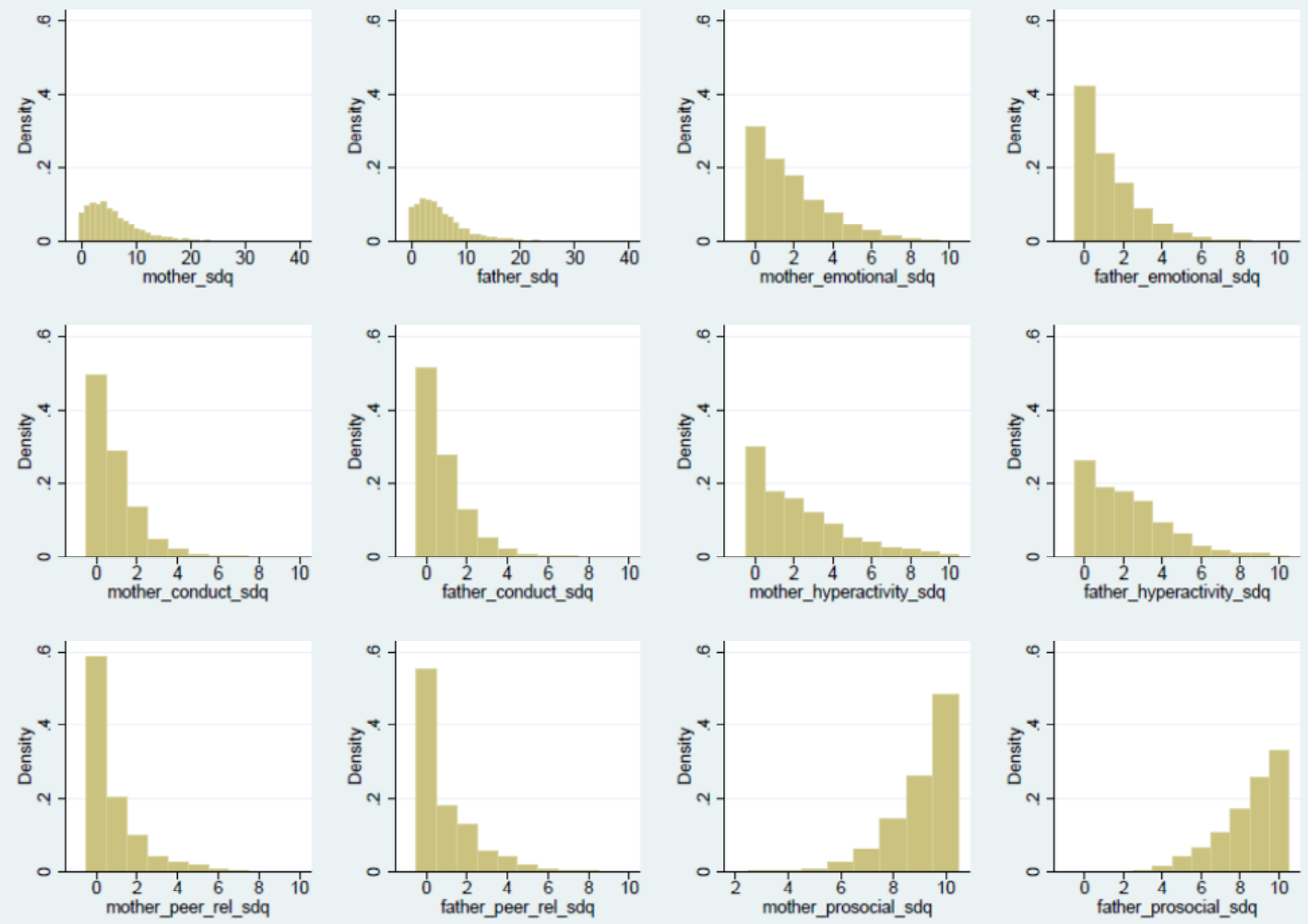
Figure 2: Distributions of parents' assessment of child academic performance
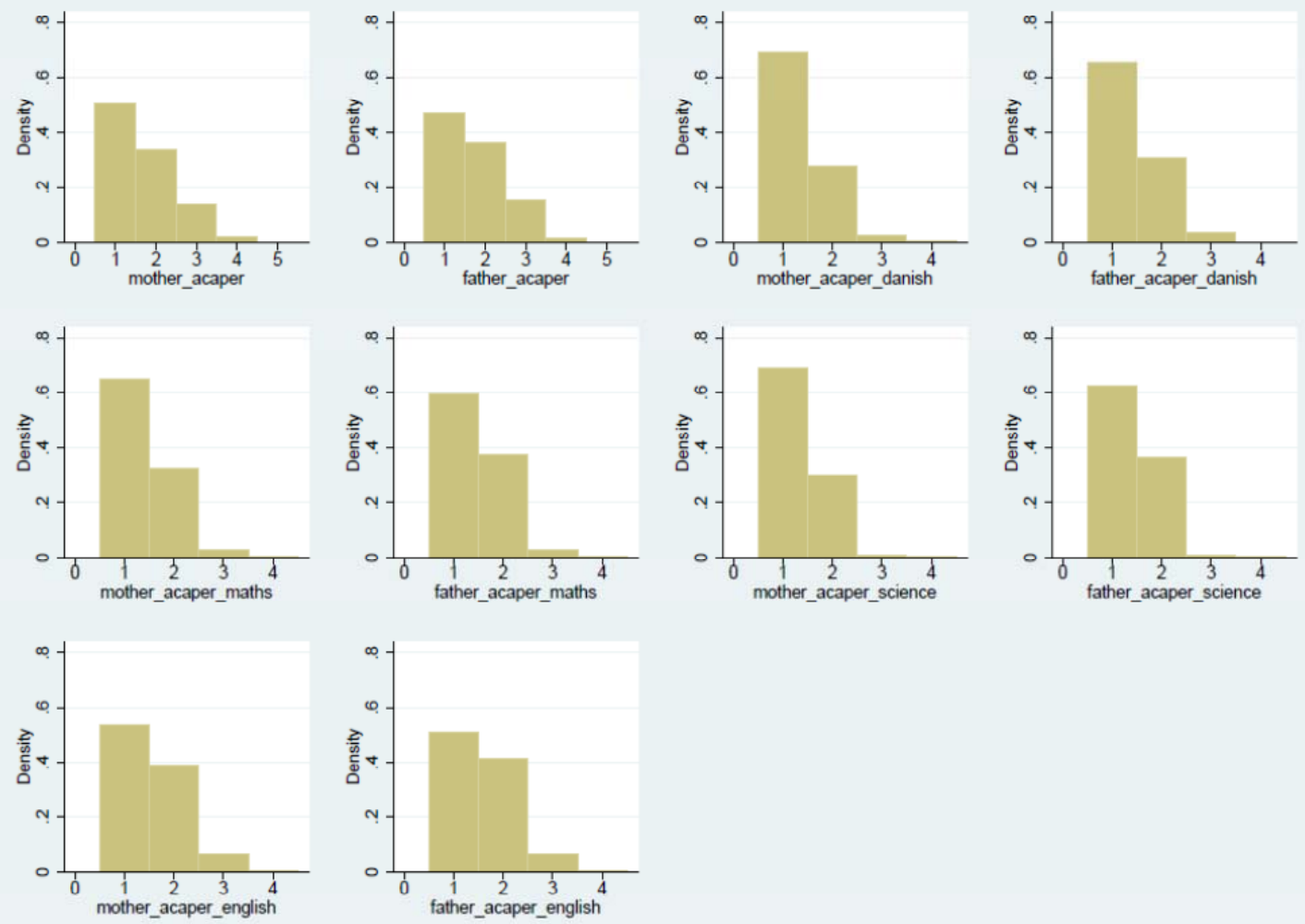
Figure 3: Distributions of parents' assessments of whether the child likes doing homework
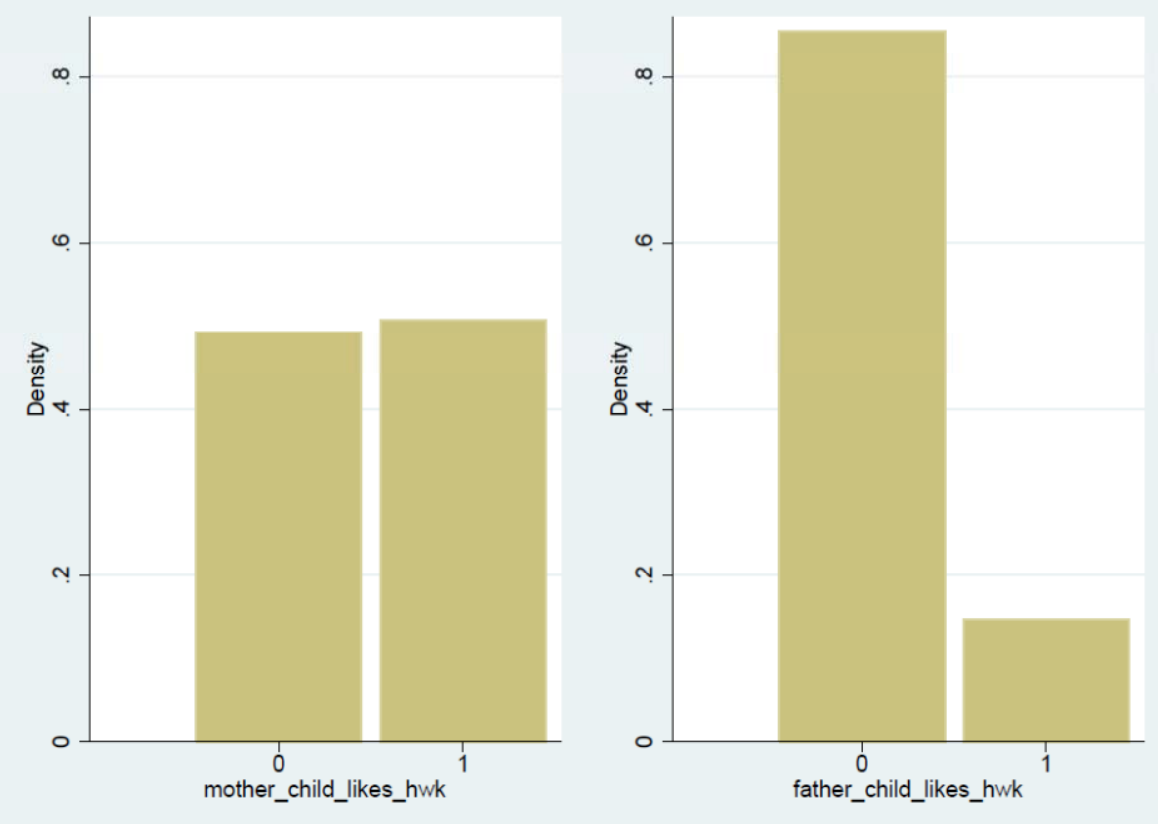
Table 1: Descriptive statistics

\begin{tabular}{|c|c|c|c|c|c|c|c|c|}
\hline & \multicolumn{4}{|c|}{ Selected sample } & \multicolumn{4}{|c|}{ Sample including disabled kids and non-intact households } \\
\hline & \multicolumn{2}{|c|}{ Girls } & \multicolumn{2}{|c|}{ Boys } & \multicolumn{2}{|c|}{ Girls } & \multicolumn{2}{|c|}{ Boys } \\
\hline & Mean & sd & Mean & sd & Mean & sd & Mean & sd \\
\hline \multicolumn{9}{|l|}{ Discrepancies variables } \\
\hline Sdq_diff (mother-father) & 0.633 & 3.558 & 0.630 & 3.754 & 0.576 & 3.754 & 0.515 & 3.957 \\
\hline Sdq_diff (mother-father), absolute value & 2.685 & 2.417 & 2.742 & 2.639 & 2.718 & 2.468 & 2.773 & 2.656 \\
\hline Acaper_diff (mother-father) & -0.029 & 0.675 & -0.057 & 0.659 & -0.027 & 0.684 & -0.062 & 0.680 \\
\hline Acaper_diff (mother-father), absolute value & 0.413 & 0.534 & 0.388 & 0.536 & 0.412 & 0.535 & 0.394 & 0.545 \\
\hline Likes_hwk(mother-father) & 0.286 & 0.629 & 0.421 & 0.569 & 0.298 & 0.628 & 0.417 & 0.570 \\
\hline \multicolumn{9}{|l|}{ Parental psychopatology } \\
\hline Mother symptoms (self-reported) & 0.185 & 0.586 & 0.184 & 0.596 & 0.196 & 0.603 & 0.205 & 0.631 \\
\hline Mother psychiatric diagnoses (2005) & 0.036 & 0.219 & 0.056 & 0.266 & 0.051 & 0.275 & 0.062 & 0.280 \\
\hline Postpartum depression & 0.027 & 0.163 & 0.033 & 0.177 & 0.029 & 0.169 & 0.037 & 0.188 \\
\hline Father symptoms (self-reported) & 0.067 & 0.352 & 0.056 & 0.313 & 0.070 & 0.362 & 0.062 & 0.335 \\
\hline Father psychiatric diagnoses (2005) & 0.037 & 0.229 & 0.053 & 0.281 & 0.037 & 0.231 & 0.061 & 0.331 \\
\hline Parents argue frequently (mother perception) & 0.096 & 0.295 & 0.085 & 0.280 & 0.092 & 0.289 & 0.084 & 0.277 \\
\hline Parents argue frequently (father perception) & 0.105 & 0.306 & 0.111 & 0.314 & 0.103 & 0.304 & 0.108 & 0.311 \\
\hline \multicolumn{9}{|l|}{ Social ties } \\
\hline Mother close relationship with the child & 0.704 & 0.457 & 0.693 & 0.461 & 0.700 & 0.459 & 0.688 & 0.464 \\
\hline Mother spending quality time with the child & 0.895 & 0.306 & 0.852 & 0.355 & 0.879 & 0.327 & 0.824 & 0.381 \\
\hline Mother work experience (2006) & 14.014 & 7.503 & 13.894 & 7.851 & 13.178 & 8.084 & 13.289 & 7.849 \\
\hline Father close relationship with the child & 0.474 & 0.500 & 0.478 & 0.500 & 0.438 & 0.496 & 0.452 & 0.498 \\
\hline Father spending quality time with the child & 0.545 & 0.498 & 0.543 & 0.498 & 0.495 & 0.500 & 0.488 & 0.500 \\
\hline Father work experience (2006) & 17.842 & 7.938 & 17.936 & 7.763 & 17.256 & 8.163 & 17.054 & 8.300 \\
\hline Father breadwinner & 0.548 & 0.498 & 0.580 & 0.494 & 0.563 & 0.496 & 0.531 & 0.499 \\
\hline Municipality provided program at age 3 & 0.852 & 0.355 & 0.919 & 0.273 & 0.849 & 0.359 & 0.925 & 0.264 \\
\hline Hours in non parental care & 30.485 & 11.070 & 31.018 & 10.844 & 30.802 & 11.018 & 31.230 & 10.681 \\
\hline \multicolumn{9}{|l|}{ Parental socioeconomic background } \\
\hline Mother secondary education & 0.413 & 0.493 & 0.416 & 0.493 & 0.412 & 0.492 & 0.403 & 0.491 \\
\hline Mother short tertiary education & 0.288 & 0.453 & 0.286 & 0.452 & 0.279 & 0.449 & 0.274 & 0.446 \\
\hline Mother medium or long tertiary education & 0.083 & 0.277 & 0.094 & 0.292 & 0.084 & 0.278 & 0.088 & 0.283 \\
\hline Father secondary education & 0.443 & 0.497 & 0.475 & 0.500 & 0.414 & 0.493 & 0.450 & 0.498 \\
\hline Father short tertiary education & 0.204 & 0.403 & 0.187 & 0.390 & 0.191 & 0.394 & 0.172 & 0.377 \\
\hline Father medium or long tertiary education & 0.121 & 0.326 & 0.129 & 0.336 & 0.111 & 0.314 & 0.115 & 0.319 \\
\hline Parents with different education & 0.551 & 0.498 & 0.542 & 0.498 & 0.547 & 0.498 & 0.545 & 0.498 \\
\hline Parents with different ethnic backround/nationality & 0.036 & 0.187 & 0.039 & 0.195 & 0.036 & 0.185 & 0.036 & 0.186 \\
\hline Household disposable income ( stated in DKK, average 2000-2006) & 380840.9 & 166079.2 & 379409.5 & 146995.9 & 356279.2 & 133484.449 & 353758.586 & 135854.734 \\
\hline \multicolumn{9}{|l|}{ Other variables } \\
\hline Child psychiatric diagnoses (2005) & 0.013 & 0.130 & 0.048 & 0.308 & 0.014 & 0.135 & 0.046 & 0.294 \\
\hline Number of older siblings & 1.129 & 1.321 & 1.118 & 1.311 & 1.114 & 1.338 & 1.044 & 1.305 \\
\hline Number of siblings & 2.258 & 0.767 & 2.291 & 0.770 & 1.118 & 1.311 & 2.291 & 0.770 \\
\hline Mother non Danish & 0.019 & 0.138 & 0.020 & 0.140 & 0.017 & 0.128 & 0.018 & 0.133 \\
\hline Father Non-Danish & 0.041 & 0.199 & 0.043 & 0.202 & 0.039 & 0.194 & 0.041 & 0.198 \\
\hline Mother age & 38.035 & 4.158 & 37.899 & 4.434 & 38.041 & 4.136 & 37.949 & 4.437 \\
\hline Father age & 40.287 & 5.235 & 40.197 & 5.445 & 40.266 & 5.215 & 40.208 & 5.402 \\
\hline Mother at least 3 years younger than father & 0.313 & 0.464 & 0.321 & 0.467 & 0.310 & 0.463 & 0.317 & 0.466 \\
\hline $\mathrm{N}$ & \multicolumn{2}{|c|}{1175} & \multicolumn{2}{|c|}{1323} & \multicolumn{2}{|c|}{1450} & \multicolumn{2}{|c|}{1671} \\
\hline
\end{tabular}


Table 2: Correlations between mother and father SDQ scores

\begin{tabular}{|c|c|c|c|c|c|c|c|c|c|c|c|c|c|}
\hline & & \multicolumn{2}{|c|}{ SDQ } & \multicolumn{2}{|c|}{ Emotion } & \multicolumn{2}{|c|}{ Conduct } & \multicolumn{2}{|c|}{ Hyperac } & \multicolumn{2}{|c|}{ Peer } & \multicolumn{2}{|c|}{ Prosoc } \\
\hline & & Mother & Father & Mother & Father & Mother & Father & Mother & Father & Mother & Father & Mother & Father \\
\hline \multirow{3}{*}{ 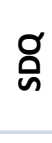 } & Mother & 1.0000 & & & & & & & & & & & \\
\hline & & & & & & & & & & & & & \\
\hline & Father & 0.6584 & 1.0000 & & & & & & & & & & \\
\hline & & 0.0000 & & & & & & & & & & & \\
\hline \multirow{3}{*}{ 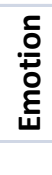 } & Mother & 0.6982 & 0.4042 & 1.0000 & & & & & & & & & \\
\hline & & 0.0000 & 0.0000 & & & & & & & & & & \\
\hline & Father & 0.4482 & 0.6698 & 0.5362 & 1.0000 & & & & & & & & \\
\hline \multirow{5}{*}{ 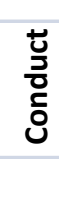 } & & 0.0000 & 0.0000 & 0.0000 & & & & & & & & & \\
\hline & Mother & 0.6728 & 0.4313 & 0.2789 & 0.1820 & 1.0000 & & & & & & & \\
\hline & & 0.0000 & 0.0000 & 0.0000 & 0.0000 & & & & & & & & \\
\hline & Father & 0.4597 & 0.7128 & 0.2018 & 0.3242 & 0.5219 & 1.0000 & & & & & & \\
\hline & & 0.0000 & 0.0000 & 0.0000 & 0.0000 & 0.0000 & & & & & & & \\
\hline \multirow{4}{*}{$\begin{array}{l}\stackrel{0}{0} \\
\stackrel{0}{0} \\
\grave{x}\end{array}$} & Mother & 0.8043 & 0.5432 & 0.3010 & 0.2384 & 0.5003 & 0.3851 & 1.0000 & & & & & \\
\hline & & 0.0000 & 0.0000 & 0.0000 & 0.0000 & 0.0000 & 0.0000 & & & & & & \\
\hline & Father & 0.5817 & 0.8074 & 0.2325 & 0.3300 & 0.3870 & 0.5301 & 0.6664 & 1.0000 & & & & \\
\hline & & 0.0000 & 0.0000 & 0.0000 & 0.0000 & 0.0000 & 0.0000 & 0.0001 & & & & & \\
\hline \multirow{4}{*}{ ఖ } & Mother & 0.6819 & 0.4800 & 0.3992 & 0.3031 & 0.3369 & 0.2596 & 0.3376 & 0.2705 & 1.0000 & & & \\
\hline & & 0.0000 & 0.0000 & 0.0000 & 0.0000 & 0.0000 & 0.0000 & 0.0000 & 0.0000 & & & & \\
\hline & Father & 0.4547 & 0.6741 & 0.2640 & 0.3528 & 0.2397 & 0.3652 & 0.2361 & 0.3262 & 0.6276 & 1.0000 & & \\
\hline & & 0.0000 & 0.0000 & 0.0000 & 0.0000 & 0.0000 & 0.0000 & 0.0000 & 0.0000 & 0.0000 & & & \\
\hline \multirow{4}{*}{ 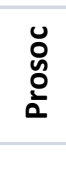 } & Mother & -0.3004 & -0.1647 & -0.1159 & -0.0388 & -0.2861 & -0.1684 & -0.247 & -0.162 & -0.25 & -0.141 & 1.0000 & \\
\hline & & 0.0000 & 0.0000 & 0.0000 & 0.1316 & 0.0000 & 0.0000 & 0.0000 & 0.0000 & 0.0000 & 0.0000 & & \\
\hline & Father & -0.3108 & -0.3837 & -0.1535 & -0.1518 & $3-0.2894$ & -0.3854 & -0.261 & -0.373 & -0.199 & -0.233 & 0.3777 & \\
\hline & & 0.0000 & 0.0000 & 0.0000 & 0.0000 & 0.0000 & 0.0000 & 0.0000 & 0.0000 & 0.0000 & 0.0000 & 0.0000 & 1.0000 \\
\hline
\end{tabular}


Table 3: Correlations between mother and father assessments of child academic performance

\begin{tabular}{|c|c|c|c|c|c|}
\hline & & \multicolumn{2}{|c|}{ Acad perf } & \multicolumn{2}{|c|}{ Likes hwk } \\
\hline & & Mother & Father & Mother & Father \\
\hline \multirow{3}{*}{$\begin{array}{l}\frac{t}{0} \\
\frac{2}{0} \\
\frac{\mathbb{Z}}{4}\end{array}$} & Mother & 1.0000 & & & \\
\hline & Father & 0.5222 & 1.0000 & & \\
\hline & & 0.0000 & & & \\
\hline \multirow{4}{*}{ 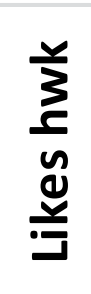 } & Mother & 0.1724 & 0.1308 & 1.0000 & \\
\hline & & 0.0000 & 0.0000 & & \\
\hline & Father & 0.2029 & 0.3245 & 0.0292 & 1.0000 \\
\hline & & 0.0000 & 0.0000 & 0.1063 & \\
\hline
\end{tabular}


Table 4: Discrepancies in ratings of child behavior, main results

\begin{tabular}{|c|c|c|c|c|c|c|c|c|c|c|c|}
\hline & (1) & (2) & (3) & (4) & (5) & (6) & (7) & (8) & (9) & (10) & (11) \\
\hline & OLS & OLS & OLS & OLS & OLS & OLS & Q25 & Q50 & Q75 & OLS & OLS \\
\hline \multicolumn{12}{|l|}{ Parental psychopatology } \\
\hline \multirow{2}{*}{ Mother symptoms } & $0.431^{* *}$ & $0.363^{* *}$ & $0.356 * *$ & & $0.356 * *$ & $0.355^{* *}$ & 0.024 & $0.276^{* *}$ & $0.391 * *$ & $0.025 * * *$ & $-0.015 * * *$ \\
\hline & $(0.149)$ & $(0.143)$ & $(0.144)$ & & $(0.145)$ & {$[(0.144)]$} & $(0.163)$ & $(0.124)$ & (0.166) & $(0.007)$ & $(0.005)$ \\
\hline \multirow[t]{2}{*}{ Mother psychiatric diagnoses } & & & & $0.288^{*}$ & & & & & & & \\
\hline & & & & $(0.152)$ & & & & & & & \\
\hline \multirow[t]{2}{*}{ Postpartum depression } & 0.202 & 0.117 & 0.114 & 0.144 & 0.103 & 0.115 & -0.513 & 0.389 & 0.484 & 0.072 & 0.047 \\
\hline & $(0.506)$ & $(0.512)$ & $(0.518)$ & $(0.517)$ & $(0.516)$ & {$[(0.518)]$} & $(0.552)$ & $(0.419)$ & $(0.561)$ & $(0.060)$ & $(0.055)$ \\
\hline \multirow{2}{*}{ Father symptoms } & -0.151 & -0.159 & -0.156 & & -0.154 & -0.158 & -0.412 & -0.259 & -0.238 & -0.015 & 0.034 \\
\hline & $(0.252)$ & $(0.256)$ & $(0.260)$ & & $(0.261)$ & $(0.260)$ & $(0.276)$ & $(0.210)$ & $(0.280)$ & $(0.028)$ & $(0.028)$ \\
\hline \multirow[t]{2}{*}{ Father psychiatric diagnoses } & & & & -0.291 & & & & & & & \\
\hline & & & & $(0.332)$ & & & & & & & \\
\hline \multirow{2}{*}{ Parents argue frequently (mother perception) } & $0.729 * *$ & $0.703^{* *}$ & $0.713^{* *}$ & $0.730^{* *}$ & $0.691^{* *}$ & $0.715^{* *}$ & 0.147 & $1.039 * * *$ & $0.830^{* *}$ & $0.140^{* * *}$ & $-0.117^{* * *}$ \\
\hline & $(0.290)$ & $(0.299)$ & $(0.301)$ & $(0.300)$ & $(0.302)$ & $(0.301)$ & $(0.334)$ & $(0.254)$ & '(0.340) & $(0.036)$ & $(0.031)$ \\
\hline \multirow[t]{2}{*}{ Parents argue frequently (father perception) } & $-0.771^{* *}$ & $-0.828 * *$ & $-0.846^{* *}$ & $-0.856 * * *$ & $-0.848 * *$ & $-0.848 * * *$ & $-0.838^{* *}$ & $-0.824 * * *$ & $-0.678^{* *}$ & $-0.074^{* *}$ & $0.053^{*}$ \\
\hline & $(0.253)$ & $(0.257)$ & $(0.257)$ & $(0.257)$ & $(0.258)$ & $(0.257)$ & $(0.310)$ & $(0.236)$ & $(0.315)$ & $(0.031)$ & $(0.031)$ \\
\hline Social ties & & & & & & & & & & & \\
\hline Mother close relationship with the child & & $-0.383^{* *}$ & $-0.374 * *$ & $-0.372 * *$ & $-0.376 * *$ & $-0.375^{* *}$ & -0.260 & $-0.423 * *$ & $-0.393^{* *}$ & $-0.034^{* *}$ & $0.032^{* *}$ \\
\hline & & $(0.168)$ & $(0.168)$ & $(0.168)$ & $(0.170)$ & $(0.168)$ & $(0.205)$ & $(0.156)$ & $(0.197)$ & $(0.010)$ & $(0.010)$ \\
\hline Mother spending quality time with the child & & 0.221 & 0.199 & 0.178 & 0.197 & 0.194 & -0.312 & 0.119 & 0.487 & 0.011 & 0.019 \\
\hline & & $(0.246)$ & $(0.248)$ & $(0.247)$ & $(0.247)$ & $(0.247)$ & $(0.302)$ & $(0.230)$ & $(0.307)$ & $(0.031)$ & $(0.028)$ \\
\hline Mother work experience & & -0.008 & -0.005 & -0.006 & -0.005 & -0.004 & 0.003 & -0.003 & -0.017 & -0.001 & 0.000 \\
\hline & & $(0.013)$ & $(0.013)$ & $(0.013)$ & $(0.013)$ & $(0.013)$ & $(0.015)$ & (0.011) & $(0.015)$ & $(0.002)$ & $(0.001)$ \\
\hline Mother close relationship with the child* child is a girl & & & & & -0.416 & & & & & & \\
\hline & & & & & $(0.333)$ & & & & & & \\
\hline Father close relationship with the child & & $0.575^{* * *}$ & $0.562^{* * *}$ & $0.563^{* * *}$ & $0.567^{* *}$ & $0.475^{* *}$ & $0.651^{* * *}$ & $0.473^{* *}$ & $0.389 * *$ & $0.041^{* *}$ & $-0.074^{* * *}$ \\
\hline & & $(0.150)$ & $(0.150)$ & (0.151) & $(0.215)$ & $(0.225)$ & $(0.190)$ & (0.144) & (0.193) & $(0.020)$ & $(0.018)$ \\
\hline Father spending quality time with the child & & -0.104 & -0.097 & -0.100 & -0.094 & -0.095 & -0.075 & -0.218 & -0.427 & -0.030 & -0.001 \\
\hline & & $(0.153)$ & $(0.153)$ & (0.153) & $(0.153)$ & $(0.153)$ & $(0.192)$ & (0.146) & $(0.245)$ & $(0.020)$ & $(0.018)$ \\
\hline Father breadwinner & & -0.013 & 0.003 & 0.016 & 0.001 & -0.070 & -0.115 & -0.017 & 0.035 & 0.010 & 0.013 \\
\hline & & $(0.192)$ & (0.195) & $(0.197)$ & $(0.195)$ & $(0.246)$ & $(0.238)$ & $(0.181)$ & $(0.242)$ & $(0.025)$ & $(0.022)$ \\
\hline Father work experience & & -0.008 & -0.007 & -0.007 & -0.007 & -0.007 & -0.007 & -0.013 & -0.008 & -0.002 & 0.001 \\
\hline & & $(0.013)$ & $(0.014)$ & $(0.014)$ & $(0.014)$ & $(0.014)$ & $(0.016)$ & $(0.012)$ & $(0.016)$ & $(0.002)$ & $(0.002)$ \\
\hline Father breadwinner*child is a girl & & & & & & 0.155 & & & & & \\
\hline & & & & & & $(0.299)$ & & & & & \\
\hline Father close relationship with the child* child is a girl & & & & & -0.009 & & & & & & \\
\hline & & & & & $(0.300)$ & & & & & & \\
\hline Municipality provided program at age 3 & & 0.199 & 0.257 & 0.225 & 0.262 & 0.259 & 0.630 & 0.023 & 0.158 & -0.023 & -0.064 \\
\hline & & $(0.331)$ & $(0.333)$ & $(0.333)$ & $(0.332)$ & $(0.333)$ & $(0.467)$ & $(0.355)$ & $(0.475)$ & $(0.046)$ & (0.043) \\
\hline Hours in non parental care & & $0.022^{*}$ & $0.020^{* *}$ & $0.021^{* *}$ & $0.020^{* *}$ & $0.020^{* *}$ & 0.007 & $0.019 * *$ & $0.026^{* *}$ & $0.003^{* *}$ & -0.001 \\
\hline & & $(0.009)$ & $(0.009)$ & $(0.009)$ & $(0.009)$ & $(0.009)$ & $(0.012)$ & $(0.009)$ & $(0.012)$ & $(0.001)$ & $(0.001)$ \\
\hline Parental socioeconomic background & & & & & & & & & & & \\
\hline Mother secondary education & & & 0.143 & 0.143 & 0.136 & 0.146 & 0.036 & 0.184 & 0.260 & 0.033 & 0.002 \\
\hline & & & $(0.214)$ & $(0.214)$ & $(0.215)$ & $(0.214)$ & $(0.261)$ & (0.199) & $(0.266)$ & $(0.027)$ & (0.024) \\
\hline Mother short tertiary education & & & -0.224 & -0.225 & -0.225 & -0.218 & -0.292 & -0.149 & $-0.486 *$ & -0.037 & 0.042 \\
\hline & & & $(0.218)$ & $(0.218)$ & $(0.218)$ & $(0.218)$ & $(0.285)$ & $(0.216)$ & $(0.289)$ & $(0.029)$ & $(0.027)$ \\
\hline Mother medium or long tertiary education & & & 0.473 & 0.436 & 0.466 & 0.482 & 0.285 & 0.174 & 0.005 & 0.036 & -0.002 \\
\hline & & & $(0.339)$ & $(0.338)$ & $(0.339)$ & $(0.341)$ & $(0.428)$ & $(0.325)$ & $(0.435)$ & $(0.045)$ & (0.038) \\
\hline Father secondary education & & & -0.297 & -0.303 & -0.300 & -0.298 & -0.226 & -0.162 & -0.381 & -0.006 & 0.028 \\
\hline & & & $(0.206)$ & $(0.206)$ & $(0.206)$ & $(0.206)$ & $(0.249)$ & $(0.189)$ & (0.253) & $(0.026)$ & $(0.024)$ \\
\hline Father short tertiary education & & & -0.020 & -0.023 & -0.024 & -0.023 & -0.064 & 0.043 & 0.132 & 0.026 & -0.016 \\
\hline & & & $(0.245)$ & $(0.245)$ & $(0.245)$ & $(0.245)$ & $(0.305)$ & $(0.232)$ & $(0.310)$ & $(0.032)$ & $(0.028)$ \\
\hline Father medium or long tertiary education & & & 0.083 & 0.092 & 0.080 & 0.080 & 0.495 & 0.362 & -0.081 & 0.024 & -0.051 \\
\hline & & & $(0.290)$ & $(0.291)$ & $(0.291)$ & $(0.290)$ & $(0.377)$ & $(0.287)$ & $(0.384)$ & $(0.039)$ & (0.034) \\
\hline Parents with different education & & & -0.190 & -0.207 & -0.191 & -0.192 & -0.206 & $-0.253^{*}$ & -0.218 & -0.013 & $0.031^{*}$ \\
\hline & & & $(0.160)$ & $(0.160)$ & $(0.160)$ & $(0.160)$ & (0.198) & $(0.151)$ & $(0.201)$ & $(0.021)$ & $(0.018)$ \\
\hline Parents with different ethnic backround/nationality & & & -0.246 & -0.244 & -0.240 & -0.242 & 0.144 & -0.160 & -0.423 & -0.042 & 0.011 \\
\hline & & & $(0.403)$ & (0.411) & $(0.403)$ & $(0.401)$ & $(0.516)$ & $(0.392)$ & $(0.524)$ & $(0.053)$ & (0.047) \\
\hline Log of household disposable income & & & -0.305 & -0.339 & -0.305 & -0.307 & -0.454 & -0.212 & -0.350 & -0.024 & $0.056^{*}$ \\
\hline & & & $(0.300)$ & (0.299) & $(0.300)$ & $(0.300)$ & $(0.374)$ & (0.284) & $(0.380)$ & $(0.041)$ & $(0.032)$ \\
\hline Other controls & & & & & & & & & & & \\
\hline Child is a girl & -0.007 & -0.010 & -0.010 & -0.008 & 0.285 & -0.009 & 0.089 & -0.221 & -0.074 & 0.009 & -0.013 \\
\hline & $(0.147)$ & $(0.149)$ & $(0.148)$ & $(0.148)$ & $(0.311)$ & $(0.149)$ & $(0.187)$ & (0.142) & $(0.190)$ & $(0.019)$ & $(0.017)$ \\
\hline Number of older siblings & 0.013 & 0.053 & 0.064 & 0.070 & 0.065 & 0.064 & $0.154^{* *}$ & 0.082 & 0.020 & 0.006 & -0.004 \\
\hline & $(0.054)$ & $(0.055)$ & $(0.055)$ & $(0.055)$ & $(0.055)$ & (0.055) & $(0.073)$ & $(0.056)$ & $(0.074)$ & $(0.008)$ & $(0.007)$ \\
\hline Mother at least 3 years younger than father & 0.064 & 0.078 & 0.064 & 0.056 & 0.060 & 0.062 & 0.273 & 0.255 & 0.157 & 0.018 & -0.008 \\
\hline & $(0.161)$ & $(0.168)$ & $(0.169)$ & $(0.168)$ & $(0.169)$ & $(0.169)$ & $(0.211)$ & (0.159) & $(0.215)$ & $(0.022)$ & $(0.019)$ \\
\hline $\mathrm{N}$ & 2382 & 2382 & 2382 & 2382 & 2382 & 2382 & 2382 & 2382 & 2382 & 2382 & 2382 \\
\hline R-sq & 0.018 & 0.031 & 0.037 & 0.037 & 0.037 & 0.037 & 0.027 & 0.028 & 0.028 & 0.029 & 0.031 \\
\hline
\end{tabular}

Notes: In columns $1,2,3,4,5,6,7,8$ and 9 the dependent variable is the difference between the mother's and the father's ratings. In column 10 (11), the dependent variable is a dummy variable equal to 1 if the mother's ratings are at least 2 scores higher (lower) than the father's ratings. Results in columns 1, 2, 3, 4 and 5 are estimates from OLS, while those in columns 6,7 and 8 are from quantile regressions. In columns 6,7 and 8 standard errors are bootstrapped (500 replications). All regressions include region dummies. Significance levels: $* * * 1 \%, * * 5 \%,{ }^{*} 10 \%$. 
Table 5: Discrepancies in ratings of child behavior, SDQ item-specific scores

\begin{tabular}{|c|c|c|c|c|c|}
\hline & (1) & (2) & (3) & (4) & (5) \\
\hline & SDQ_EMO & SDQ_CON & SDQ_HYPER & SDQ_PEER & SDQ_PROS \\
\hline \multicolumn{6}{|l|}{ Parental psychopatology } \\
\hline \multirow[t]{2}{*}{ Mother symptoms } & $0.305^{* * *}$ & $0.041^{* * *}$ & 0.012 & $0.057 * * *$ & $0.093^{*}$ \\
\hline & $(0.070)$ & $(0.023)$ & $(0.064)$ & $(0.017)$ & $(0.049)$ \\
\hline \multirow[t]{2}{*}{ Postpartum depression } & 0.162 & 0.014 & -0.069 & -0.061 & -0.002 \\
\hline & $(0.231)$ & $(0.125)$ & $(0.266)$ & $(0.156)$ & $(0.170)$ \\
\hline \multirow[t]{2}{*}{ Father symptoms } & 0.072 & $-0.146 * *$ & 0.053 & -0.129 & 0.104 \\
\hline & $(0.110)$ & $(0.067)$ & $(0.126)$ & $(0.087)$ & $(0.082)$ \\
\hline \multirow[t]{2}{*}{ Parents argue frequently (mother perception) } & 0.154 & 0.115 & $0.422^{* *}$ & 0.028 & $-0.221^{*}$ \\
\hline & (0.119) & (0.091) & (0.139) & $(0.106)$ & $(0.116)$ \\
\hline \multirow[t]{2}{*}{ Parents argue frequently (father perception) } & $-0.191^{*}$ & $-0.164^{* *}$ & $-0.319 * *$ & $-0.178^{* *}$ & $0.237^{* *}$ \\
\hline & $(0.117)$ & $(0.081)$ & $(0.119)$ & $(0.088)$ & $(0.109)$ \\
\hline \multicolumn{6}{|l|}{ Social ties } \\
\hline \multirow[t]{2}{*}{ Mother close relationship with the child } & $-0.033^{* *}$ & $-0.161 * *$ & $-0.170^{* *}$ & -0.0230 & $0.121^{* *}$ \\
\hline & $(0.014)$ & $(0.049)$ & $(0.078)$ & $(0.058)$ & $(0.059)$ \\
\hline \multirow[t]{2}{*}{ Mother spending quality time with the child } & -0.019 & 0.027 & 0.096 & 0.110 & $-0.171^{*}$ \\
\hline & $(0.118)$ & (0.071) & $(0.117)$ & $(0.086)$ & (0.104) \\
\hline \multirow[t]{2}{*}{ Mother work experience } & -0.007 & 0.001 & -0.002 & 0.002 & 0.000 \\
\hline & $(0.006)$ & $(0.004)$ & $(0.006)$ & $(0.004)$ & $(0.005)$ \\
\hline \multirow[t]{2}{*}{ Father close relationship with the child } & 0.055 & $0.157^{* * *}$ & $0.244^{* * *}$ & $0.105^{* *}$ & $-0.520^{* * *}$ \\
\hline & $(0.070)$ & $(0.043)$ & (0.071) & (0.051) & $(0.061)$ \\
\hline \multirow[t]{2}{*}{ Father spending quality time with the child } & -0.044 & -0.028 & -0.014 & -0.004 & $-0.121^{*}$ \\
\hline & $(0.070)$ & (0.044) & $(0.073)$ & $(0.052)$ & $(0.063)$ \\
\hline \multirow[t]{2}{*}{ Father breadwinner } & 0.010 & -0.023 & -0.042 & 0.042 & -0.046 \\
\hline & (0.088) & $(0.055)$ & (0.091) & $(0.066)$ & (0.079) \\
\hline \multirow[t]{2}{*}{ Father work experience } & 0.003 & -0.003 & -0.003 & -0.003 & 0.006 \\
\hline & $(0.006)$ & $(0.004)$ & $(0.006)$ & $(0.005)$ & $(0.005)$ \\
\hline \multirow[t]{2}{*}{ Municipality provided program at age 3} & 0.047 & 0.003 & 0.138 & 0.152 & $-0.263^{*}$ \\
\hline & $(0.167)$ & (0.098) & $(0.166)$ & $(0.129)$ & $(0.155)$ \\
\hline \multirow[t]{2}{*}{ Hours in non parental care } & 0.007 & 0.002 & $0.010^{* *}$ & -0.001 & $0.007^{*}$ \\
\hline & $(0.004)$ & (0.003) & $(0.004)$ & $(0.003)$ & $(0.004)$ \\
\hline Parental socioeconomic background & & & & & \\
\hline Mother secondary education & 0.093 & 0.021 & -0.001 & 0.036 & 0.108 \\
\hline & (0.098) & $(0.063)$ & (0.104) & $(0.073)$ & $(0.084)$ \\
\hline Mother short tertiary education & -0.077 & 0.010 & $-0.176 *$ & 0.018 & 0.135 \\
\hline & $(0.103)$ & $(0.064)$ & (0.107) & $(0.075)$ & $(0.090)$ \\
\hline Mother medium or long tertiary education & 0.215 & 0.111 & -0.064 & 0.196 & $-0.210^{*}$ \\
\hline & $(0.156)$ & (0.094) & $(0.157)$ & $(0.123)$ & $(0.127)$ \\
\hline Father secondary education & -0.070 & -0.015 & -0.118 & -0.098 & 0.114 \\
\hline & (0.093) & $(0.063)$ & (0.099) & $(0.071)$ & $(0.082)$ \\
\hline Father short tertiary education & 0.031 & -0.064 & 0.018 & -0.005 & -0.117 \\
\hline & $(0.113)$ & $(0.069)$ & $(0.119)$ & $(0.085)$ & $(0.101)$ \\
\hline Father medium or long tertiary education & -0.020 & -0.002 & 0.002 & 0.084 & $-0.195^{*}$ \\
\hline & $(0.127)$ & $(0.086)$ & $(0.135)$ & $(0.102)$ & $(0.118)$ \\
\hline Parents with different education & 0.003 & -0.025 & $-0.159 * *$ & -0.018 & 0.055 \\
\hline & $(0.073)$ & $(0.047)$ & $(0.077)$ & $(0.056)$ & $(0.066)$ \\
\hline Parents with different ethnic backround/nationality & -0.204 & $0.195^{*}$ & $-0.307^{*}$ & 0.073 & 0.057 \\
\hline & (0.194) & $(0.117)$ & $(0.190)$ & $(0.113)$ & $(0.172)$ \\
\hline Log of household disposable income & -0.149 & 0.013 & -0.205 & 0.063 & 0.084 \\
\hline & $(0.137)$ & (0.091) & $(0.144)$ & $(0.103)$ & $(0.112)$ \\
\hline Other controls & & & & & \\
\hline Child is a girl & 0.094 & $0.118^{* *}$ & $-0.150^{* *}$ & -0.067 & -0.045 \\
\hline & $(0.069)$ & $(0.043)$ & $(0.071)$ & $(0.051)$ & $(0.061)$ \\
\hline Number of older siblings & -0.009 & -0.003 & $0.049^{*}$ & 0.027 & 0.005 \\
\hline & $(0.026)$ & $(0.016)$ & $(0.027)$ & $(0.020)$ & $(0.025)$ \\
\hline Mother at least 3 years younger than father & -0.041 & 0.034 & 0.024 & 0.046 & -0.042 \\
\hline & $(0.078)$ & $(0.048)$ & $(0.083)$ & $(0.056)$ & $(0.069)$ \\
\hline $\mathrm{N}$ & 2389 & 2390 & 2390 & 2388 & 2408 \\
\hline R-sq & 0.027 & 0.026 & 0.031 & 0.022 & 0.061 \\
\hline
\end{tabular}

Notes: The dependent variable is the difference between the mother's and the father's ratings. All regressions include region dummies. Significance levels: $* * * 1 \%, * * 5 \%,{ }^{*} 10 \%$. 
Table 6: Discrepancies in ratings of child academic performance, main results

\begin{tabular}{|c|c|c|c|c|c|c|c|c|}
\hline & (1) & (2) & (3) & (4) & (5) & (6) & (7) & (8) \\
\hline & ACAPER_MF & ACAPER_MF & ACAPER_MF & ACAPER_MF & ACAPER_MF & ACAPER_MF & ACAPER_MF & ACAPER_MF \\
\hline \multicolumn{9}{|l|}{ Parental psychopatology } \\
\hline \multirow[t]{2}{*}{ Mother symptoms } & $-0.146 *$ & $-0.143^{*}$ & $0.162^{* *}$ & $0.177^{*}$ & $0.164^{* *}$ & $0.162^{* *}$ & $0.029 *$ & $-0.026 * *$ \\
\hline & $(0.077)$ & $(0.077)$ & $(0.078)$ & $(0.092)$ & $(0.078)$ & (0.078) & $(0.015)$ & $(0.013)$ \\
\hline \multirow[t]{2}{*}{ Mother psychiatric diagnoses } & & & & -0.023 & & & & \\
\hline & & & & $(0.024)$ & & & & \\
\hline \multirow[t]{2}{*}{ Postpartum depression } & -0.020 & -0.023 & -0.022 & & -0.022 & -0.023 & 0.072 & $-0.069 *$ \\
\hline & $(0.024)$ & $(0.024)$ & $(0.024)$ & & $(0.024)$ & $(0.024)$ & $(0.054)$ & $(0.037)$ \\
\hline \multirow[t]{2}{*}{ Father symptoms } & 0.027 & 0.035 & 0.031 & & 0.032 & 0.031 & 0.040 & 0.038 \\
\hline & $(0.055)$ & $(0.055)$ & $(0.055)$ & & $(0.055)$ & $(0.055)$ & $(0.028)$ & $(0.028)$ \\
\hline \multirow[t]{2}{*}{ Father psychiatric diagnoses } & & & & -0.079 & & & & \\
\hline & & & & $(0.045)$ & & & & \\
\hline \multirow[t]{2}{*}{ Parents argue frequently (mother perception) } & 0.049 & 0.054 & 0.053 & 0.054 & 0.048 & 0.053 & -0.033 & 0.020 \\
\hline & $(0.046)$ & $(0.048)$ & (0.048) & $(0.048)$ & (0.048) & $(0.048)$ & $(0.030)$ & $(0.028)$ \\
\hline \multirow[t]{2}{*}{ Parents argue frequently (father perception) } & -0.064 & -0.045 & -0.046 & -0.045 & -0.046 & -0.046 & 0.039 & -0.017 \\
\hline & $(0.045)$ & $(0.046)$ & $(0.047)$ & $(0.046)$ & $(0.047)$ & $(0.047)$ & $(0.030)$ & $(0.024)$ \\
\hline \multicolumn{9}{|l|}{ Social ties } \\
\hline \multirow[t]{2}{*}{ Mother close relationship with the child } & & $-0.075^{* *}$ & $-0.072^{* *}$ & $-0.070^{* *}$ & $-0.034^{* * *}$ & $-0.072^{* *}$ & $0.054^{* *}$ & $-0.069^{* * *}$ \\
\hline & & $(0.030)$ & $(0.031)$ & $(0.031)$ & $(0.013)$ & $(0.031)$ & $(0.018)$ & $(0.018)$ \\
\hline Mother spending quality time with the child & & 0.060 & 0.049 & 0.053 & 0.049 & 0.049 & -0.023 & -0.011 \\
\hline & & $(0.045)$ & $(0.045)$ & $(0.045)$ & $(0.045)$ & $(0.045)$ & $(0.028)$ & $(0.025)$ \\
\hline Mother work experience & & 0.001 & 0.002 & 0.002 & 0.002 & 0.002 & -0.001 & 0.000 \\
\hline & & $(0.002)$ & $(0.002)$ & $(0.002)$ & $(0.002)$ & $(0.002)$ & $(0.001)$ & $(0.001)$ \\
\hline Mother close relationship with the child* child is a girl & & & & & -0.081 & & & \\
\hline & & & & & $(0.062)$ & & & \\
\hline Father close relationship with the child & & $0.063^{* *}$ & $0.061^{* *}$ & $0.060^{* *}$ & $0.073^{* *}$ & $0.052^{* *}$ & $-0.043^{* *}$ & $0.038^{* * *}$ \\
\hline & & $(0.027)$ & $(0.028)$ & $(0.028)$ & $(0.029)$ & $(0.020)$ & $(0.017)$ & $(0.016)$ \\
\hline Father spending quality time with the child & & 0.022 & 0.027 & 0.027 & 0.027 & 0.027 & -0.018 & 0.011 \\
\hline & & $(0.028)$ & $(0.028)$ & $(0.028)$ & $(0.028)$ & $(0.028)$ & $(0.017)$ & $(0.016)$ \\
\hline Father breadwinner & & -0.024 & -0.018 & -0.023 & -0.018 & -0.023 & 0.016 & -0.003 \\
\hline & & $(0.034)$ & $(0.034)$ & $(0.034)$ & $(0.034)$ & $(0.043)$ & $(0.021)$ & (0.019) \\
\hline Father work experience & & 0.001 & 0.001 & 0.001 & 0.001 & 0.001 & 0.000 & 0.001 \\
\hline & & $(0.002)$ & $(0.002)$ & $(0.002)$ & $(0.002)$ & $(0.002)$ & $(0.001)$ & $(0.001)$ \\
\hline Father breadwinner*child is a girl & & & & & & -0.023 & & \\
\hline & & & & & & $(0.055)$ & & \\
\hline Father close relationship with the child* child is a girl & & & & & 0.010 & & & \\
\hline & & & & & $(0.055)$ & & & \\
\hline Municipality provided program at age 3 & & $-0.112^{*}$ & -0.086 & -0.080 & -0.085 & -0.086 & $0.070^{*}$ & -0.009 \\
\hline & & $(0.065)$ & $(0.065)$ & $(0.064)$ & $(0.065)$ & $(0.065)$ & $(0.040)$ & $(0.037)$ \\
\hline Hours in non parental care & & -0.000 & -0.001 & -0.001 & -0.001 & -0.001 & -0.001 & -0.001 \\
\hline & & $(0.002)$ & $(0.002)$ & $(0.002)$ & $(0.002)$ & $(0.002)$ & $(0.001)$ & $(0.001)$ \\
\hline Parental socioeconomic background & & & & & & & & \\
\hline Mother secondary education & & & -0.022 & -0.024 & -0.024 & -0.022 & 0.002 & -0.002 \\
\hline & & & $(0.041)$ & $(0.041)$ & $(0.041)$ & $(0.041)$ & $(0.024)$ & $(0.022)$ \\
\hline Mother short tertiary education & & & -0.042 & -0.043 & -0.042 & -0.041 & -0.005 & -0.030 \\
\hline & & & $(0.042)$ & $(0.042)$ & $(0.042)$ & $(0.042)$ & $(0.026)$ & $(0.023)$ \\
\hline Mother medium or long tertiary education & & & 0.074 & 0.079 & 0.072 & 0.074 & $-0.072^{* *}$ & 0.011 \\
\hline & & & $(0.058)$ & $(0.059)$ & $(0.058)$ & $(0.058)$ & $(0.036)$ & $(0.035)$ \\
\hline Father secondary education & & & -0.025 & -0.024 & -0.026 & -0.025 & -0.002 & -0.014 \\
\hline & & & $(0.039)$ & $(0.039)$ & $(0.039)$ & $(0.039)$ & $(0.023)$ & $(0.021)$ \\
\hline Father short tertiary education & & & $-0.122^{* *}$ & $-0.121^{* *}$ & $-0.122^{* *}$ & $-0.122^{* *}$ & 0.029 & $-0.067^{* *}$ \\
\hline & & & $(0.044)$ & $(0.044)$ & $(0.044)$ & $(0.044)$ & $(0.028)$ & $(0.024)$ \\
\hline Father medium or long tertiary education & & & -0.031 & -0.029 & -0.031 & -0.031 & -0.022 & -0.041 \\
\hline & & & $(0.050)$ & $(0.050)$ & $(0.050)$ & $(0.050)$ & $(0.033)$ & $(0.029)$ \\
\hline Parents with different education & & & -0.004 & -0.001 & -0.004 & -0.004 & -0.026 & -0.017 \\
\hline & & & $(0.030)$ & $(0.030)$ & $(0.030)$ & $(0.030)$ & $(0.018)$ & $(0.016)$ \\
\hline Parents with different ethnic background/nationality & & & 0.004 & 0.019 & 0.004 & 0.004 & -0.012 & 0.004 \\
\hline & & & $(0.072)$ & $(0.072)$ & $(0.073)$ & $(0.072)$ & $(0.047)$ & $(0.041)$ \\
\hline Log of household disposable income & & & 0.001 & 0.004 & -0.000 & 0.001 & -0.026 & -0.018 \\
\hline & & & $(0.056)$ & $(0.055)$ & (0.056) & $(0.056)$ & $(0.031)$ & $(0.033)$ \\
\hline Other controls & & & & & & & & \\
\hline Child is a girl & 0.026 & 0.027 & 0.030 & 0.029 & $0.098^{*}$ & 0.030 & -0.009 & 0.025 \\
\hline & $(0.027)$ & $(0.027)$ & $(0.027)$ & $(0.027)$ & $(0.057)$ & $(0.027)$ & $(0.017)$ & $(0.015)$ \\
\hline Number of older siblings & $0.020^{*}$ & 0.017 & 0.016 & 0.015 & 0.016 & 0.016 & -0.009 & $0.010^{*}$ \\
\hline & $(0.011)$ & $(0.011)$ & $(0.011)$ & $(0.011)$ & $(0.011)$ & $(0.011)$ & $(0.007)$ & $(0.006)$ \\
\hline Mother at least 3 years younger than father & -0.002 & -0.009 & -0.011 & -0.010 & -0.012 & -0.011 & 0.021 & 0.019 \\
\hline & $(0.030)$ & $(0.031)$ & $(0.031)$ & $(0.031)$ & -0.031 & $(0.031)$ & $(0.019)$ & $(0.017)$ \\
\hline $\mathrm{N}$ & 2466 & 2394 & 2388 & 2388 & 2388 & 2388 & 2388 & 2388 \\
\hline R-sq & 0.008 & 0.015 & 0.021 & 0.021 & 0.022 & 0.021 & 0.026 & 0.018 \\
\hline
\end{tabular}

Notes: The dependent variable is the difference between the mother's and the father's ratings. In columns $7(8)$, the dependent variable is the mother's rating is worse (better) than the father's. All regressions include region dummies. Significance levels: $* * * 1 \%, * * 5 \%, * 10 \%$. 
Table 7: Discrepancies in ratings of child academic performance, subject-specific assessments, and in ratings of whether the child likes doing homework

\begin{tabular}{|c|c|c|c|c|c|}
\hline & ACAPER_DANISH & ACAPER_MATHS & ACAPER_SCIENCE & ACAPER_ENGLISH & Likes_hwk_MF \\
\hline \multicolumn{6}{|l|}{ Parental psychopatology } \\
\hline \multirow[t]{2}{*}{ Mother symptoms } & 0.015 & $0.193^{* *}$ & $0.086^{* *}$ & 0.006 & $-0.104^{* *}$ \\
\hline & (0.098) & $(0.090)$ & $(0.032)$ & $(0.018)$ & $(0.032)$ \\
\hline \multirow[t]{2}{*}{ Postpartum depression } & -0.010 & 0.006 & -0.003 & 0.011 & -0.047 \\
\hline & $(0.031)$ & $(0.028)$ & $(0.017)$ & $(0.017)$ & $(0.068)$ \\
\hline \multirow[t]{2}{*}{ Father symptoms } & 0.012 & -0.010 & -0.005 & -0.009 & 0.029 \\
\hline & $(0.058)$ & $(0.050)$ & $(0.033)$ & $(0.030)$ & $(0.021)$ \\
\hline \multirow[t]{2}{*}{ Parents argue frequently (mother perception) } & 0.101 & 0.042 & 0.004 & 0.024 & -0.000 \\
\hline & $(0.064)$ & $(0.065)$ & $(0.037)$ & $(0.042)$ & $(0.040)$ \\
\hline \multirow[t]{2}{*}{ Parents argue frequently (father perception) } & 0.017 & 0.048 & -0.028 & -0.039 & 0.004 \\
\hline & $(0.057)$ & $(0.056)$ & $(0.035)$ & $(0.036)$ & (0.039) \\
\hline \multicolumn{6}{|l|}{ Social ties } \\
\hline \multirow[t]{2}{*}{ Mother close relationship with the child } & $-0.030 * * *$ & -0.047 & $-0.036^{*}$ & $-0.037^{* *}$ & $0.043^{*}$ \\
\hline & (0.011) & $(0.037)$ & $(0.022)$ & $(0.016)$ & $(0.026)$ \\
\hline \multirow[t]{2}{*}{ Mother spending quality time with the child } & 0.010 & -0.032 & 0.042 & 0.023 & 0.035 \\
\hline & $(0.058)$ & $(0.055)$ & $(0.032)$ & $(0.034)$ & $(0.039)$ \\
\hline \multirow[t]{2}{*}{ Mother work experience } & $0.004^{*}$ & 0.003 & 0.000 & 0.002 & 0.003 \\
\hline & $(0.003)$ & $(0.003)$ & $(0.002)$ & $(0.002)$ & $(0.002)$ \\
\hline \multirow[t]{2}{*}{ Father close relationship with the child } & 0.016 & $0.077^{* *}$ & $0.038^{*}$ & $0.039 * *$ & $-0.040^{*}$ \\
\hline & $(0.034)$ & $(0.035)$ & $(0.020)$ & $(0.018)$ & $(0.025)$ \\
\hline \multirow[t]{2}{*}{ Father spending quality time with the child } & 0.024 & -0.007 & 0.031 & 0.029 & -0.029 \\
\hline & $(0.035)$ & $(0.035)$ & $(0.020)$ & $(0.022)$ & $(0.025)$ \\
\hline \multirow[t]{2}{*}{ Father breadwinner } & 0.035 & 0.068 & 0.016 & -0.012 & 0.011 \\
\hline & $(0.043)$ & $(0.043)$ & $(0.025)$ & $(0.027)$ & $(0.031)$ \\
\hline \multirow[t]{2}{*}{ Father work experience } & 0.003 & 0.002 & $-0.004 * *$ & -0.002 & -0.003 \\
\hline & $(0.003)$ & $(0.003)$ & $(0.002)$ & $(0.002)$ & $(0.002)$ \\
\hline \multirow[t]{2}{*}{ Municipality provided program at age 3} & -0.032 & 0.054 & -0.062 & -0.026 & -0.012 \\
\hline & $(0.083)$ & $(0.082)$ & $(0.060)$ & $(0.048)$ & $(0.058)$ \\
\hline \multirow[t]{2}{*}{ Hours in non parental care } & -0.001 & -0.000 & 0.001 & -0.001 & $0.003^{* *}$ \\
\hline & $(0.002)$ & $(0.002)$ & $(0.002)$ & $(0.001)$ & $(0.001)$ \\
\hline \multicolumn{6}{|l|}{ Parental socioeconomic background } \\
\hline Mother secondary education & 0.057 & 0.072 & 0.008 & -0.014 & 0.015 \\
\hline & (0.049) & (0.049) & $(0.029)$ & $(0.031)$ & $(0.034)$ \\
\hline Mother short tertiary education & -0.015 & 0.019 & -0.003 & -0.032 & 0.020 \\
\hline & (0.051) & $(0.051)$ & $(0.030)$ & (0.031) & $(0.037)$ \\
\hline Mother medium or long tertiary education & -0.069 & $-0.139 *$ & 0.039 & 0.040 & 0.070 \\
\hline & $(0.073)$ & $(0.073)$ & $(0.041)$ & $(0.045)$ & $(0.055)$ \\
\hline Father secondary education & -0.032 & -0.024 & 0.000 & 0.002 & 0.009 \\
\hline & $(0.048)$ & $(0.047)$ & $(0.028)$ & $(0.030)$ & $(0.033)$ \\
\hline Father short tertiary education & $-0.125^{* *}$ & -0.024 & -0.006 & 0.004 & 0.016 \\
\hline & $(0.055)$ & $(0.056)$ & $(0.032)$ & $(0.035)$ & $(0.041)$ \\
\hline Father medium or long tertiary education & -0.102 & -0.086 & 0.042 & 0.040 & 0.052 \\
\hline & (0.066) & $(0.066)$ & $(0.033)$ & $(0.040)$ & $(0.049)$ \\
\hline Parents with different education & 0.026 & 0.017 & 0.006 & -0.002 & 0.010 \\
\hline & $(0.036)$ & $(0.036)$ & $(0.021)$ & $(0.023)$ & $(0.026)$ \\
\hline Parents with different ethnic background/nationality & $-0.146^{*}$ & -0.150 & -0.065 & 0.052 & -0.017 \\
\hline & $(0.087)$ & $(0.097)$ & (0.049) & $(0.050)$ & $(0.072)$ \\
\hline Log of household disposable income & 0.031 & 0.022 & 0.025 & $-0.067^{*}$ & 0.034 \\
\hline & $(0.072)$ & $(0.075)$ & $(0.042)$ & (0.039) & $(0.050)$ \\
\hline Other controls & & & & & \\
\hline Child is a girl & -0.016 & $-0.059^{*}$ & 0.012 & -0.016 & $-0.137^{* * *}$ \\
\hline & $(0.034)$ & $(0.034)$ & $(0.020)$ & $(0.021)$ & $(0.024)$ \\
\hline Number of older siblings & 0.001 & -0.015 & -0.006 & $0.015^{*}$ & -0.012 \\
\hline & $(0.014)$ & $(0.014)$ & $(0.008)$ & $(0.008)$ & $(0.010)$ \\
\hline Mother at least 3 years younger than father & -0.019 & -0.011 & 0.017 & 0.037 & -0.036 \\
\hline & $(0.038)$ & $(0.038)$ & $(0.022)$ & $(0.024)$ & $(0.028)$ \\
\hline $\mathrm{N}$ & 2286 & 2261 & 2402 & 2400 & 2388 \\
\hline$R-s q$ & 0.016 & 0.021 & 0.014 & 0.014 & 0.037 \\
\hline
\end{tabular}

Notes: The dependent variable is the difference between the mother's and the father's ratings. All regressions include region dummies. Significance levels: $* * * 1 \%, * * 5 \%, * 10 \%$. 
Table 8: Generalized ordered probit results of parental assessments of child academic performance

\begin{tabular}{|c|c|c|c|c|c|c|}
\hline \multirow{2}{*}{ Child academic performance } & \multicolumn{2}{|c|}{ General academic performance } & \multicolumn{2}{|c|}{ Math performance } & \multicolumn{2}{|c|}{ Danish performance } \\
\hline & Mother & Father & Mother & Father & Mother & Father \\
\hline \multicolumn{7}{|l|}{ Objective measures } \\
\hline \multirow[t]{2}{*}{ Chips score } & $-0.028^{* * *}$ & $-0.032^{\star * *}$ & $-0.051^{* * *}$ & $-0.049^{* * *}$ & & \\
\hline & $(0.006)$ & $(0.006)$ & $(0.009)$ & $(0.009)$ & & \\
\hline \multirow{3}{*}{ Language test } & $-0.099^{* * *}$ & $-0.089^{* * *}$ & & & $-0.079^{* * *}$ & $-0.059^{\star \star \star}$ \\
\hline & $(0.006)$ & $(0.006)$ & & & $(0.011)$ & $(0.011)$ \\
\hline & \multicolumn{2}{|c|}{ Threshold for "very well" } & \multicolumn{2}{|c|}{ Threshold for "very well" } & \multicolumn{2}{|c|}{ Threshold for "very well" } \\
\hline \multicolumn{7}{|l|}{ Parental psychopatology } \\
\hline \multirow{2}{*}{ Mother symptoms } & 0.014 & & $-0.212^{\star \star}$ & & -0.068 & \\
\hline & $(0.059)$ & & $(0.077)$ & & $(0.098)$ & \\
\hline Postpartum depression & 0.043 & & 3.895 & & 0.343 & \\
\hline & $(0.207)$ & & $(8.617)$ & & $(0.467)$ & \\
\hline Father symptoms & & $\quad-0.126$ & & $-0.300^{* *}$ & & $-0.362^{\star *}$ \\
\hline & & $(0.093)$ & & $(0.115)$ & & $(0.112)$ \\
\hline Parents argue frequently (mother perception) & $-0.351^{* *}$ & & $-0.485^{\star *}$ & & -0.139 & \\
\hline & $(0.113)$ & & $(0.167)$ & & $(0.219)$ & \\
\hline Parents argue frequently (father perception) & & $-0.136^{* * *}$ & & -0.150 & & -0.157 \\
\hline & & $(0.006)$ & & $(0.193)$ & & $(0.198)$ \\
\hline Social ties & & & & & & \\
\hline Mother close relationship with the child & $0.311^{\star \star \star}$ & & $0.272^{\star \star}$ & & $0.281^{\star *}$ & \\
\hline & $(0.075)$ & & $(0.126)$ & & $(0.142)$ & \\
\hline Mother spending quality time with the child & -0.071 & & -0.140 & & -0.236 & \\
\hline & $(0.116)$ & & $(0.216)$ & & $(0.258)$ & \\
\hline Mother work experience & -0.006 & & 0.007 & & 0.005 & \\
\hline & $(0.006)$ & & $(0.010)$ & & $(0.011)$ & \\
\hline Father close relationship with the child & & $0.318^{\star \star *}$ & & $0.258^{* *}$ & & $0.248^{\star \star}$ \\
\hline & & $(0.070)$ & & $(0.114)$ & & $(0.119)$ \\
\hline Father spending quality time with the child & & $0.167^{* *}$ & & 0.066 & & 0.083 \\
\hline & & $(0.069)$ & & $(0.110)$ & & $(0.116)$ \\
\hline Father breadwinner & & -0.005 & & $-0.016^{*}$ & & -0.004 \\
\hline & & $(0.006)$ & & $(0.010)$ & & $(0.010)$ \\
\hline Father work experience & & $\quad-0.105$ & & 0.009 & & -0.012 \\
\hline & & $(0.080)$ & & $(0.127)$ & & $(0.133)$ \\
\hline Municipality provided program at age 3 & $0.264^{*}$ & 0.087 & -0.193 & 0.025 & 0.103 & -0.159 \\
\hline & $(0.165)$ & $(0.163)$ & $(0.318)$ & $(0.274)$ & $(0.297)$ & $(0.307)$ \\
\hline Hours in non parental care & -0.006 & -0.003 & 0.004 & -0.004 & -0.002 & -0.005 \\
\hline & $(0.004)$ & $(0.004)$ & $(0.008)$ & $(0.007)$ & $(0.008)$ & $(0.007)$ \\
\hline Parental socioeconomic background & & & & & & \\
\hline Mother secondary education & -0.027 & & 0.072 & & 0.135 & \\
\hline & $(0.092)$ & & $(0.151)$ & & $(0.165)$ & \\
\hline Mother short tertiary education & 0.025 & & $0.407^{\star *}$ & & 0.152 & \\
\hline & $(0.103)$ & & $(0.193)$ & & $(0.189)$ & \\
\hline Mother medium or long tertiary education & 0.158 & & 0.175 & & -0.015 & \\
\hline & $(0.165)$ & & $(0.284)$ & & $(0.299)$ & \\
\hline Father secondary education & & 0.115 & & -0.027 & & -0.205 \\
\hline & & $(0.086)$ & & $(0.138)$ & & $(0.152)$ \\
\hline Father short tertiary education & & 0.054 & & -0.011 & & -0.135 \\
\hline & & $(0.106)$ & & $(0.175)$ & & $(0.191)$ \\
\hline Father medium or long tertiary education & & $0.410^{* *}$ & & 0.279 & & 0.136 \\
\hline & & $(0.140)$ & & $(0.263)$ & & $(0.277)$ \\
\hline Non Danish mother & 0.115 & & 4.065 & & 3.676 & \\
\hline & $(0.403)$ & & $(3.824)$ & & $(2.142)$ & \\
\hline Non Danish father & & -0.047 & & 0.133 & & 0.192 \\
\hline & & $(0.226)$ & & $(0.442)$ & & $(0.460)$ \\
\hline Log of household disposable income & -0.008 & -0.003 & $0.491^{*}$ & 0.090 & 0.183 & -0.036 \\
\hline & $(0.135)$ & $(0.029)$ & $(0.251)$ & $(0.242)$ & $(0.231)$ & $(0.246)$ \\
\hline Other controls & & & & & & \\
\hline Child is a girl & 0.004 & 0.078 & -0.278 & $-0.336^{*}$ & $0.261^{*}$ & $-0.425^{*}$ \\
\hline & $(0.069)$ & $(0.069)$ & $(0.176)$ & $(0.173)$ & $(0.138)$ & $(0.221)$ \\
\hline Number of older siblings & $-0.013^{\star \star \star}$ & -0.024 & -0.052 & 0.017 & 0.056 & 0.047 \\
\hline & $(0.001)$ & $(0.026)$ & $(0.046)$ & $(0.043)$ & $(0.053)$ & $(0.046)$ \\
\hline Mother age & -0.001 & & -0.016 & & $-0.033^{*}$ & \\
\hline & $(0.010)$ & & $(0.018)$ & & $(0.019)$ & \\
\hline Father age & & 0.009 & & 0.013 & & 0.009 \\
\hline & & $(0.008)$ & & $(0.013)$ & & $(0.013)$ \\
\hline $\bar{N}$ & 2382 & 2382 & 2382 & 2382 & 2382 & 2382 \\
\hline
\end{tabular}

Notes: The dependent variable is the parent's assessment of the child school performance. Significance levels: ***1\%, **5\%, ${ }^{*} 10 \%$. 
Table 9: Estimated coefficients for the linear factor model of child functioning

\begin{tabular}{|c|c|c|c|c|}
\hline & \multicolumn{2}{|c|}{ FULL SAMPLE } & GIRLS & BOYS \\
\hline & \multicolumn{4}{|c|}{ CHIPS SCORES } \\
\hline & \multicolumn{4}{|c|}{ (S.E.); [BETA COEFF.] } \\
\hline \multirow[t]{3}{*}{ Acaper_mother } & $-0.948^{* * *}$ & & $-0.862 * * *$ & $-1.010^{* * *}$ \\
\hline & $(0.165)$ & & $(0.213)$ & $(0.247)$ \\
\hline & {$[-0.144]$} & & {$[-0.145]$} & {$[-0.145]$} \\
\hline \multirow[t]{3}{*}{ Acaper_father } & $-1.361^{* * *}$ & & $-1.022^{* * *}$ & $-1.591^{* * *}$ \\
\hline & $(0.165)$ & & $(0.215)$ & $(0.245)$ \\
\hline & {$[-0.208]$} & & {$[-0.170]$} & {$[-0.230]$} \\
\hline \multirow[t]{3}{*}{ Acaper_math_mother } & & $-1.300^{* * *}$ & & \\
\hline & & $(0.210)$ & & \\
\hline & & {$[-0.138]$} & & \\
\hline \multirow[t]{3}{*}{ Acaper_math_father } & & $-1.189 * * *$ & & \\
\hline & & $(0.204)$ & & \\
\hline & & {$[-0.130]$} & & \\
\hline \multicolumn{5}{|l|}{ Hypothesis tests } \\
\hline Aca_mother=Acaper_father: Chi2; $p$-value & $1.92 ; 0.167$ & & $0.17 ; 0.67$ & $1.68 ; 0.19$ \\
\hline \multirow[t]{3}{*}{ Acaper_math_mother=Acaper_math_father: Chi2; $\mathrm{p}$-value } & & $0.09 ; 0.761$ & & \\
\hline & \multicolumn{4}{|c|}{ LANGUAGE TEST SCORES } \\
\hline & & (S.E. & EFF.] & \\
\hline \multirow{3}{*}{ Aca_mother } & $-1.827^{* * *}$ & & $-1.749 * * *$ & $-1.889 * * *$ \\
\hline & $(0.148)$ & & (0.196) & $(0.219)$ \\
\hline & {$[-0.288]$} & & {$[-0.296]$} & {$[-0.284]$} \\
\hline \multirow[t]{3}{*}{ Aca_father } & $-1.481^{* * *}$ & & $-1.263^{* * *}$ & $-1.615^{* * *}$ \\
\hline & $(0.148)$ & & (0.197) & $(0.217)$ \\
\hline & {$[-0.234]$} & & {$[-0.213]$} & {$[-0.245]$} \\
\hline \multirow[t]{3}{*}{ Aca_danish_mother } & & $-2.266^{* * *}$ & & \\
\hline & & $(0.199)$ & & \\
\hline & & {$[-0.239]$} & & \\
\hline \multirow[t]{3}{*}{ Aca_danish_father } & & $-2.063^{* * *}$ & & \\
\hline & & $(0.190)$ & & \\
\hline & & {$[-0.229]$} & & \\
\hline \multicolumn{5}{|l|}{ Hypothesis tests } \\
\hline Aca_mother=Acaper_father: Chi2; $p$-value & $1.67 ; 0.197$ & & $1.91 ; 0.16$ & $0.48 ; 0.49$ \\
\hline \multirow[t]{3}{*}{ Acaper_math_mother=Acaper_math_father: Chi2; $\mathrm{p}$-value } & & $0.34 ; 0.557$ & & \\
\hline & \multicolumn{4}{|c|}{ PSYCHIATRIC DIAGNOSES } \\
\hline & \multicolumn{4}{|c|}{ (S.E.); [BETA COEFF.] } \\
\hline \multirow[t]{3}{*}{ Sdq_mother } & $0.007^{* * *}$ & $0.007^{* * *}$ & $0.005^{* * *}$ & $0.008^{* * *}$ \\
\hline & $(0.001)$ & $(0.001)$ & $(0.001)$ & $(0.002)$ \\
\hline & [0.190] & [0.189] & {$[0.197]$} & {$[0.192]$} \\
\hline \multirow[t]{3}{*}{ Sdq_father } & $0.004^{* * *}$ & $0.004^{* * *}$ & $0.004^{* *}$ & $0.005^{* *}$ \\
\hline & $(0.001)$ & $(0.001)$ & $(0.001)$ & $(0.002)$ \\
\hline & [0.101] & [0.098] & {$[0.114]$} & {$[0.095]$} \\
\hline \multicolumn{5}{|l|}{ Hypothesis tests } \\
\hline Sdq_mother=Sdq_father: Chi2; $p$-value & $2.47 ; 0.116$ & $2.59 ; 0.10$ & $1.19 ; 0.29$ & $1.39 ; 0.23$ \\
\hline $\bar{N}$ & 2389 & 2389 & 1130 & 1248 \\
\hline Log-likelihood & -12910.1 & -12965.2 & -5532.8 & -7159.5 \\
\hline
\end{tabular}

Notes: The equations for the CHIPS scores, language test scores and psychiatric diagnoses are estimated simultaneously by maximum likelihood. Significance levels: $* * * 1 \%, * * 5 \%, * 10 \%$. 